\title{
A review of the role of cav- 1 in neuropathology and neural recovery after ischemic stroke
}

\author{
Qianyi Huang, Wei Zhong, Zhiping Hu and Xiangqi Tang ${ }^{*}$
}

\begin{abstract}
Ischemic stroke starts a series of pathophysiological processes that cause brain injury. Caveolin-1 (cav-1) is an integrated protein and locates at the caveolar membrane. It has been demonstrated that cav-1 can protect blood-brain barrier (BBB) integrity by inhibiting matrix metalloproteases (MMPs) which degrade tight junction proteins. This article reviews recent developments in understanding the mechanisms underlying BBB dysfunction, neuroinflammation, and oxidative stress after ischemic stroke, and focuses on how cav-1 modulates a series of activities after ischemic stroke. In general, cav-1 reduces BBB permeability mainly by downregulating MMP9, reduces neuroinflammation through influencing cytokines and inflammatory cells, promotes nerve regeneration and angiogenesis via cav-1NEGF pathway, reduces apoptosis, and reduces the damage mediated by oxidative stress. In addition, we also summarize some experimental results that are contrary to the above and explore possible reasons for these differences.
\end{abstract}

Keywords: Ischemic stroke, Cav-1, BBB permeability, Neurogenesis, Angiogenesis, Neuroinflammation, Apoptosis, Oxidative stress

\section{Introduction}

Stroke is a common cerebrovascular event and is one of the leading causes of mortality and morbidity worldwide. Ischemic stroke (IS) and hemorrhagic stroke are the two major categories of stroke, and IS is more common, accounting for $87 \%$ of all strokes [1]. IS is caused by a blocked blood vessel as a result of a thrombus or embolus and leads to hypoxia and loss of glucose in the cerebral tissue that survives [2]. Intensive basic and clinical studies have revealed a variety of stroke risk factors and elucidated many mechanisms of ischemic brain injury. Cerebral ischemia initiates multiple pathophysiological processes, including vasogenic edema, excitotoxicity, disruption of the blood-brain barrier (BBB), oxidative stress, cerebral inflammation, and neuronal death [3, 4]. Although significant progress has been made in understanding the pathophysiology of IS, patients with acute brain ischemia still lack treatment options.

Administration of tissue plasminogen activator (tPA) is the most effective treatment option for cerebral ischemia several years ago [5], but its use is limited to a narrow window after the onset of stroke, as the risk of

* Correspondence: txq6633@csu.edu.cn

Department of Neurology, The Second Xiangya Hospital, Central South University, Renmin Road 139\#, Changsha 410011, Hunan, China hemorrhagic transformation increases over time, causing increased brain damage. Since 2015, mechanical thrombectomy has become the first-line treatment for anterior circulation stroke with proximal large-artery occlusion. However, only about $20 \%$ of stroke patients have large-artery occlusion and it is a challenge to deliver treatment to them within the 24-h time window because the procedure can only be performed in highly specialized centers [6]. In general, for more patients who cannot accept thrombolysis or mechanical thrombectomy, it is essential to elucidate the molecular mechanisms underlying IS and explore potential therapeutic targets to restore function after stroke.

The caveolae of the cell membrane are invaginations of the plasma membrane with an omega shape and a diameter of $60-80 \mathrm{~nm}$ which are rich in cholesterol and glycosphingolipids [7]. The caveolin family of proteins, which includes caveolin-1 (cav-1), caveolin-2, and caveolin-3, are located in cell membrane caveolae [8]. Cav-1 is the major component, is a specific marker of caveolae, and is generally distributed in smooth muscle cells, endothelial cells, skeletal myoblasts, fibroblasts, and adipocytes [9]. Cav-1 modulates a wide range of cellular events such as proliferation, lipid metabolism, cellular tracking, and signal transduction [10]. Cav-1 has also demonstrated a beneficial 
role in IS. In this review, we discuss how caveolins modulate BBB permeability and the relationships between cav-1 and a series of processes including neurogenesis, angiogenesis, neuroinflammation, apoptosis, and oxidative stress in IS.

\section{Pathophysiological mechanisms in IS: BBB damage, inflammation, and free radicals}

In acute IS, an embolic or thrombotic event usually results in a rapid reduction in blood supply to a specific brain region, temporarily or permanently. The glucose and oxygen supply to the brain decreases, causing a rapid decline in ATP and a subsequent large movement of $\mathrm{Ca}^{2+}$ from the extracellular to the intracellular space [11]. Because of a lack of energy, the membrane ion pump which includes the $\mathrm{Na}^{+}-\mathrm{K}^{+}$-ATPase fails to efflux intracellular sodium and this is a fundamental reason for cytotoxic edema [12]. BBB damage further exacerbates brain edema and cerebral injury [13]. Middle cerebral artery occlusion (MCAO) with reperfusion leads to a biphasic disruption of the $\mathrm{BBB}$ [14]. The initial opening is reversible and is associated with the activation of MMP-2. The second opening of the $\mathrm{BBB}$ is mediated by MMP-3 and MMP-9 which are induced by inflammatory cytokines [15]. Matrix metalloproteases (MMPs) are a group of endopeptidases that cleave protein substrates including fibronectin, laminin, proteoglycans, and type-IV collagen based on $\mathrm{Zn}^{2+}$ ion [16]. The early degradation of tight junction (TJ) proteins appears to be associated with MMP-2 in the early period of ischemia, and direct injection of MMP-2 into the rat brain disrupts the BBB [17]. However, MMP-2 knockout did not provide neuroprotection in a rodent MCAO stroke model [18]. This may indicate that MMP-2 is not the major deleterious enzyme in the MMP response to ischemic stroke. In contrast, knockout of the MMP-9 gene demonstrates significant neuroprotection in an MCAO animal model [19]. Although inhibition or knockout of MMP-9 attenuates early degradation of the $\mathrm{BBB}$ in MCAO models, it is ineffective in preventing later opening of the BBB at $48 \mathrm{~h}$ after IS, and MMP-9 is thought to be beneficial in later stroke recovery, especially in promoting angiogenesis and neurogenesis $[8,20]$. Therefore, it remains a challenge to identify agents that restore the integrity of the $\mathrm{BBB}$ and prevent brain edema without intervening in recovery.

Post-ischemic inflammation is another critical factor in the evolution of cerebral damage in IS models. In the first few hours after IS, microglial cells resident in the brain are activated and release toxic proinflammatory cytokines. These cytokines enable leukocytes to transmigrate across the endothelium and exacerbate brain infarction [21, 22]. Following microglial activation, peripheral macrophages, lymphocytes, and dendritic cells migrate to the site of injury, which precedes a neutrophil influx [23]. The infiltrating neutrophils promote $\mathrm{BBB}$ breakdown, resulting in deteriorating stroke outcomes. Inhibiting the upregulation of neutrophil integrins can ameliorate inflammatory responses and BBB dysfunction after ischemia [24]. It has been shown that neutrophils in the infarct core produce MMP-9 after IS and MMP-9 can further promote leukocyte recruitment. This positive feedback contributes to serious BBB breakdown and neuronal injury [25]. In terms of lymphocytes, Yilmaz et al. has shown that CD4 ${ }^{+}$ (helper T cells, Th) and $\mathrm{CD} 8^{+} \mathrm{T}$ cells (cytotoxic T cells, $\mathrm{Tc}$ ) are promotors of brain infarction and contributors to inflammatory responses after IS [26]. Previous studies have found that $\mathrm{CD} 4^{+}$Th1 cells secrete pro-inflammatory cytokines, such as interferon gamma, and lymphotoxin alpha in stroke, whereas $\mathrm{CD} 4^{+} \mathrm{Th} 2$ produce anti-inflammatory cytokines including IL-4, IL-10, and IL-13 [27]. Contrary to Th cells, the role of regulatory cells (Tregs) after ischemia is controversial. Liesz et al. found an increase in delayed brain damage in Treg-deficient mice, but less secondary infarct growth after the re-expression of Treg cells [28]. However, Kleinschnitz et al. showed that knockout of endogenous Tregs can reduce the cerebral volume of infarction and improve functional outcomes [29]. Another study has clearly demonstrated that depletion of $\mathrm{B}$ cells profoundly increases infarct volumes and mortality and impairs neurological function [30].

Free radicals and reactive species are thought to play major roles in cerebral ischemia reperfusion (I/R) injury. Reactive species include reactive oxygen species (ROS) and reactive nitrogen species (RNS). Huge quantities of ROS are produced following ischemia reperfusion, and they can increase brain damage through different mechanisms. For instance, ROS can destroy some cellular macromolecules contributing to autophagy, apoptosis, and necrosis [31]. ROS enhance inflammatory responses by activating inflammation factors and promoting leucocyte infiltration [32]. Furthermore, free radicals can affect BBB permeability through different ways. For example, ROS can oxidize and peroxidize proteins and lipids, and peroxidation of membrane lipids can directly damage BBB integrity [33]. ROS can also activate ProMMPs which degrade TJ proteins, further inducing BBB hyperpermeability. Reduction of ROS through the knockdown of NADPH oxidase blocks the upregulation of MMP-9 by inhibiting nuclear factor- $\mathrm{kB}$ (NF-kB)-dependent MMP-9 promoter activity [34]. ROS produced by the xanthine/xanthine oxidase system can directly redistribute $\mathrm{TJ}$ proteins by acting on the Rho, PI3K, and PKB pathways [35]. RNS, typically including $\mathrm{NO}$ and peroxynitrite, mediate $\mathrm{BBB}$ damage and functional deficits following IS. Physiological concentrations of $\mathrm{NO}$ are essential for a variety of processes, including neuronal communication, vascular tone regulation, and synaptic transmission [36, 37]. High concentrations of $\mathrm{NO}$ can induce inflammation and apoptotic cell death, resulting in a larger infarction size, which is detrimental to 
the ischemic brain tissue [38, 39]. RNS also mediate MMP activation in cerebral I/R injury [40]. Thus, reducing free radicals could be an effective mechanism for protection in acute ischemic stroke.

\section{Caveolae and caveolins}

Caveolae were first observed by Palade and Yamada independently in the 1950s [41]. Caveolins and cavins have been found to be critical for the caveolae formation. Cavin, which is also termed polymerase I and transcript release factor, is an adapter protein that forms oligomers and assists in membrane curvature [42]. Caveolins are $22-24 \mathrm{kDa}$ integral membrane proteins which are divided into three groups, caveolin-1, caveolin-2, and caveolin-3, with an $\mathrm{NH}_{2}$-terminal membrane attachment domain and a $\mathrm{COOH}$-terminal membrane attachment domain that bind to membranes with high affinity, and both the Nand C-termini face the cytoplasm [43, 44]. Cav-1 and cav-2 are ubiquitously distributed, while cav-3 is primarily expressed in vascular smooth muscle, skeletal, and cardiac muscle cells. However, cav-3 has also been detected in astrocytes, neurons, and microglial cells $[45,46]$. In the brain, cav- 1 and cav- 2 are primarily expressed in endothelial cells, and cav-3 is expressed in astrocytes [47, 48]. Human cav- 1 and human cav- 3 share $65 \%$ sequence identity and $85 \%$ sequence similarity and display similar activities [49]. Cav-2 shares $38 \%$ sequence identity and $58 \%$ sequence similarity with cav-1 [50], but unlike cav- 1 , cav-2 is not essential for caveolae formation. In cav-2-deficient mice, although the expression of cav-1 is decreased, the formation of caveolae is not affected [51]. Caveolins contain several separate domains: an $\mathrm{N}$-terminal domain (residues 1-53), a caveolin-scaffolding domain (CSD) (residues 54-73), a transmembrane domain (residues 74-106), and a C-terminal domain (residues 107151) [52]. Cav- 1 and cav-3 interact with many proteins through the CSD. The CSD binds to caveolin-binding motifs (CBDs). This binding motif is characterized by the amino acid sequence: ФХФXXXXФ, ФХXXXФXXФ, ФХФХХХХФХХФ, where $\Phi$ is an aromatic residue, such as tyrosine, tryptophan, or phenylalanine, and $\mathrm{X}$ is any amino acid [53]. The CSD functions as a docking site for many intracellular signaling proteins. For example, CBD binding to the CSD usually inhibits a diverse range of proteins, such as eNOS, epithelial growth factor receptor, PKA, PKC, G proteins, and Src family proteins. Moreover, the CSD has also been described as an activator of insulin receptor signaling $[54,55]$.

Functionally, caveolae are important in endocytosis, oncogenesis, and phagocytosis [56]. Caveolins can bind and regulate proteins with the CBD including NOS, MMP2, and epidermal growth factor receptor (EGFR), and they are involved in numerous cellular activities such as apoptosis [57], cholesterol transport [58], and cancer metastasis [59, 60]. Cav-1, a well-established major structural protein of caveolae, has been suggested as playing an important role in the regulation of multiple cellular processes, including cell growth, differentiation, endocytosis, cholesterol trafficking, and cellular senescence [61]. Interestingly, it has been shown that cav-1 regulates the anti-atherogenic properties of macrophage, but cav-1 promotes atherosclerosis in endothelial cells $[62,63]$. In the cerebrum, cav-1 regulates neuronal signaling and promotes dendritic growth [64]. Changes in cav-1 can sequentially induce a series of alterations in BBB permeability, neuroinflammation, cerebral angiogenesis, apoptosis, and oxidative stress, which we will discuss in detail.

\section{Important role of cav-1 in IS}

Recently, it has been shown that cav-1 has a beneficial role in cerebral ischemia. Overexpression (OE) of cav-1 decreased brain edema following photothrombosis and $\mathrm{MCAO}$ in rats [65]. Knockout (KO) of the cav-1-encoding gene in mice produced an enlargement in infarction size, impaired angiogenesis, and increased apoptotic cell death compared with wild-type (cav-1(+/+)) mice and cav-2-deficient (cav-2(-/-)) mice [66]. Recently, Choi et al. found that cav-1 KO mice showed a dramatic increase in the extent of BBB disruption compared with wild-type mice, and this effect was inhibited by lentiviral-mediated re-expression of cav-1 [67]. However, some researchers believe that the protective effects in brain ischemia of several natural active compounds are related to the reduced expression of cav-1. Zhang et al. showed that green tea polyphenols could reduce BBB permeability and brain edema, and this neuroprotection effect may be related to the downregulation of cav-1 and phosphorylated ERK1/2 [68]. Huang et al. also found that post-infarct treatment with Cerebralcare Granule significantly decreased the elevated $\mathrm{BBB}$ permeability in the ischemic region, which was associated with the inhibition of cav-1 in the endothelial cells [69]. The discrepancy is probably due to the multifaceted role of natural objects and different stroke models. Their protective role in ischemic stroke is not necessarily due to the reduction of cav- 1 , and there is no further intervention on cav-1. Further studies are still needed to confirm if reduced cav- 1 is one of the mechanisms of the protective effects of natural compounds. The following discussion is about the role of cav-1 in ischemic stroke.

\section{Cav-1 regulates BBB permeability in stroke (Fig. 1)}

It is well established that cav-1 is closely related to BBB permeability in stroke. Experimental models of cerebral ischemia indicate that the downregulation of cav-1 membrane protein results in increased BBB permeability [70]. In a clinical study, low serum levels of caveolin-1 were considered to be a predictor of symptomatic 


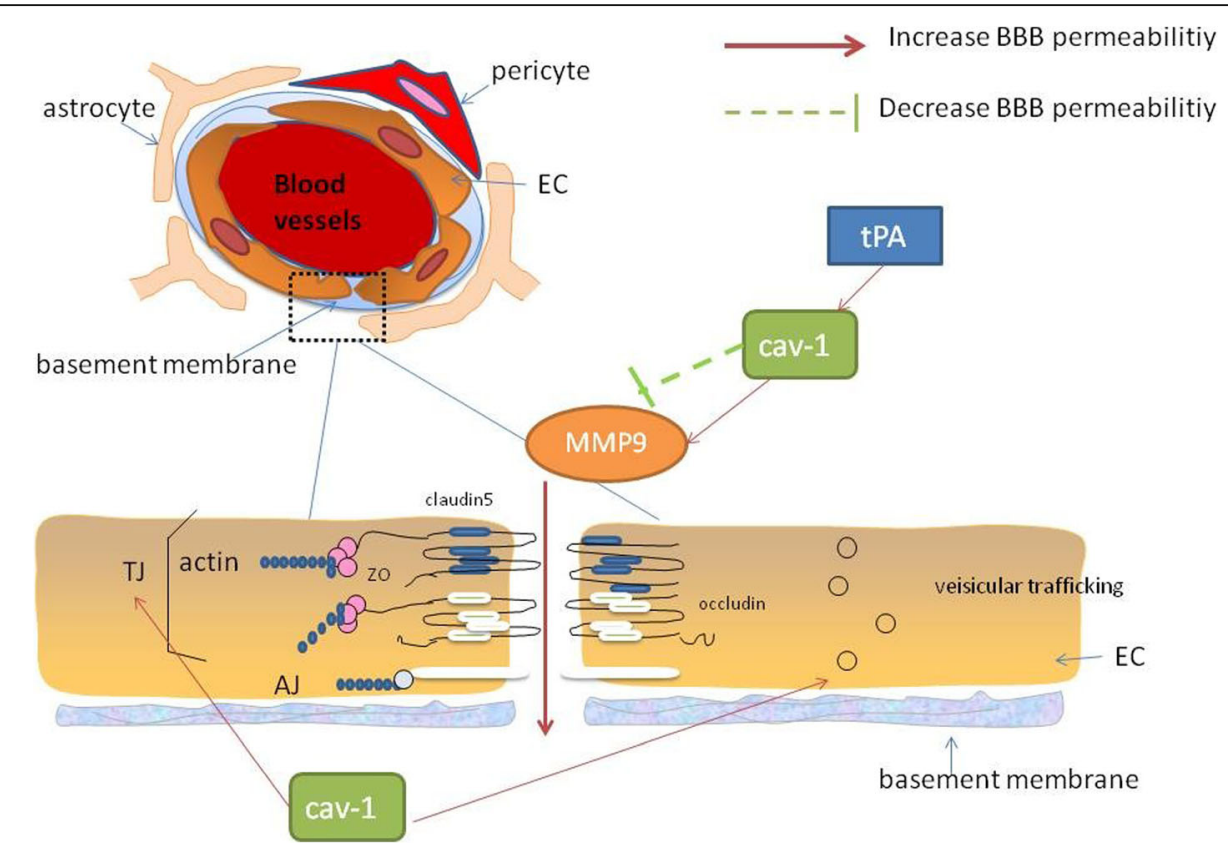

Fig. 1 Effect of caveolin-1 (cav-1) on the blood-brain barrier (BBB). Cav-1 increases the BBB permeability via caveolae-based transcytosis and translocation of tight junction (TJ) protein. Cav-1 inhibits matrix metalloproteinase-9 (MMP-9) which disrupts TJ proteins and basement membrane under ischemic stroke condition, while cav-1 appears to promote MMP-9 upregulation by tPA. However, cav-1 (-/-) mice demonstrated higher MMP activity and BBB permeability than cav-1(+/+) mice in a focal cerebral ischemia-reperfusion model, which means that cav-1 may mainly protects BBB integrity after IS. Endothelial cell (EC), ischemic stroke (IS), tight junction (TJ): actin ZO claudin 5 occludin

hemorrhagic transformation (sHT). sHT is related to increased endothelial permeability after $\mathrm{r}$-tPA administration [71].

Cav-1 predominantly regulates BBB permeability through transcellular and paracellular routes. There are 14-fold fewer vesicles in the brain endothelium than in the endothelium of non-neural vessels, which demonstrates the unique properties of central nervous system (CNS) endothelial cells: their limited vesicular transport (transcytosis). Numerous macromolecules, including albumin, lipoproteins, insulin, and transferrin, have been shown to be transendothelially delivered through caveolae [72]. Phoneutria nigriventer spider venom-induced $\mathrm{BBB}$ opening is relevant to increased expression of cav-1 $\alpha$ [73]. Cav-1 KO mice showed defects in the uptake and transport of albumin from the blood to the interstitium [74]. Co-administration of focused ultrasound and a dose of microbubbles resulted in a high expression of cav-1 and increased BBB permeability through a caveolae-mediated transcellular mechanism [75]. Feng et al. demonstrated that vascular endothelial growth factor (VEGF) enhanced retinal endothelial cell permeability via eNOS-dependent transcytosis in caveolae [76]. Knowland et al. showed that the increased endothelial caveolae number and transcytosis rate account for early BBB hyperpermeability after MCAO [77]. Therefore, it is considered that cav-1 can increase the $\mathrm{BBB}$ permeability via caveolae-based transcytosis.
Caveolae-mediated transport is regulated by Src-mediated phosphorylation. To regulate caveola formation and fission, it is essential to orchestrate the localization and activity of proteins of the endocytic machinery [78]. Src-mediated phosphorylation of caveolin-1 at Tyr14 initiates plasmalemmal vesicle fission and transendothelial vesicular transport [79]. Sun et al. observed that phosphorylation of cav-1 is crucial in $\mathrm{H}_{2} \mathrm{O}_{2}$ exposure-induced pulmonary vascular hyperpermeability, which occurs through transcellular and paracellular pathways [80]. In terms of the regulatory mechanism of cav-1 phosphorylation, Takeuchi et al. showed that oxidative stress-induced cav-1 phosphorylation and endocytosis was inhibited by the activation of AMPK, in part by suppressing the dissociation between c- $\mathrm{Abl}$ and Prdx1 proteins [81]. Andreone et al. reported the regulation of CNS endothelial cell lipid composition specifically inhibited the caveolae-mediated transcytosis [82].

Decreased levels of TJs typically increase BBB permeability. Cav-1 affects paracellular permeability by controlling MMPs. Cav-1-deficient mice showed higher MMP proteolytic activity and breakdown of $\mathrm{TJ}$ proteins than wild type mice, and the opposite effects were observed following re-expression of cav-1 [67]. Downregulation of cav-1 led to decreased expression of TJ-associated proteins, proteolysis of TJs, and opening of the blood-tumor barrier (BTB), whereas cav-1 OE restored the expression of TJ-associated proteins [83]. Gu et al. found that cav-1 
in the ischemic region was reduced after focal cerebral ischemia with reperfusion. The decreased cav-1 was associated with enhanced activities of MMP-2 and MMP-9 activity, downregulation of zonula occludens- 1 expression, and increased $\mathrm{BBB}$ permeability. The researchers used two methods, including cav-1 knockdown in cultured brain microvascular endothelial cells (BMECs) and a cav-1 gene KO mouse model. Cav-1 knockdown resulted in high MMP activity and BMEC hyperpermeability. Cav-1(-/-) mice demonstrated higher MMP activity and BBB permeability than cav-1 $(+/+)$ mice in a focal cerebral ischemia-reperfusion model [70]. Interestingly, cav-1 seems to play a role in $\mathrm{PPA}$-induced MMP-9 activation in the ischemic brain, which exaggerates brain infarction and increases the risk of symptomatic cerebral hemorrhage. To determine whether cav-1 is involved in tPA-induced MMP-9 upregulation, cultured BMECs were treated using cav-1 siRNA. It was shown that knockdown of cav-1 blocked tPA-induced MMP-9 mRNA increases and increases in MMP-9 protein levels in the conditioned media, but did not affect decreased MMP-9 levels in cellular extracts. It means that cav-1 may not affect MMP-9 secretion from the endothelial cells [84]. However, Song et al. reported that cav-1 s-nitrosylation is involved in the secretion of MMP-2 and MMP-9 from tPA-treated ischemic endothelial cells. In the context of tPA-induced ERK activation, oxygen-glucose deprivation (OGD)-triggered cav-1 s-nitrosylation can enhance MMP-2 and MMP-9 secretion and subsequently promote extracellular matrix (ECM) degradation [85]. Taken together, cav-1 inhibits MMP-9 under ischemic stroke condition. In contrast, cav-1 appears to promote MMP-9 upregulation by tPA. These findings give us a hint that the effect of cav- 1 may be stimulus-dependent. And more work is needed to clarify the signaling mechanisms.

Cav-1 is also connected with the distribution of TJ proteins. Liu et al. found that MMP-2 was responsible for OGD-induced occludin degradation, and in vitro, cav-1 mediated claudin-5 redistribution in OGD [86]. They further investigated the fate of translocated claudin- 5 and the mechanisms through which OGD promoted cav-1 translocation, and their data demonstrate that NO promotes the delivery of claudin- 5 to the autophagosome for autophagy-lysosome-dependent degradation which is mediated by cav-1 [87]. Caveolae also mediate the internalization of TJ proteins, including occludin and claudin- 5 , when brain endothelial cells are exposed to chemokine (C-C motif) ligand 2 (CCL2) which induces TJ remodeling [88].

Contrary to the view that cav-1 is neuroprotective in cerebral ischemia, there are a host of studies demonstrating that cav- 1 may damage the BBB. To simulate this situation, three models of high BBB permeability were established, including MCAO insult, lipopolysaccharide (LPS) treatment, and cold injury. In these models, the expression of both claudin-5 and VE-cadherin was reduced, whereas cav-1 protein expression was increased [89]. In rats with cerebral ischemia-reperfusion injury, Xie et al. demonstrated that inhibiting transient receptor potential vanilloid 4 ameliorated $\mathrm{BBB}$ disruption through reducing the expression of cav-1 and cav-2 [90]. Pretreatment with electroacupuncture profoundly ameliorated the elevated $\mathrm{BBB}$ permeability and reduced brain edema in a focal $I / R$ rat model, and it was related to the decreased degradation of TJ proteins and downregulation of the expression of p-cav-1 in endothelial cells [91]. The discrepancy in previous studies may arise from different ischemia models, different time of ischemia-reperfusion, or different sample sources. In general, cav-1 can increase BBB permeability through caveolae-mediated endocytosis and translocation of $\mathrm{TJ}$ protein, but can also protect $\mathrm{BBB}$ integrity by inhibiting MMP activity during ischemic stroke.

\section{Cav-1 and angiogenesis (Fig. 2)}

Angiogenesis refers to the sprouting of new microvessels from existing vasculature. It is a process of endothelial proliferation, migration, and differentiation and is often stimulated by hypoxia [92]. Both in humans and rodents, angiogenesis takes place in the area surrounding a brain infarction, starting 3-4 days after the ischemic insult [93, 94]. Upon the onset of ischemia, NO and VEGF lead to vasodilation and increased vascular permeability, resulting in extravasation of plasma proteins. Subsequently, these proteins lay down a temporary scaffold for the migration of endothelial cells which is necessary for vascular sprouting [95], and then angiopoietin-2 dissociates smooth muscle cells and loosens the ECM [96]. Following complete restructuring of the ECM, ECM tracts are formed [92]. ECM tracts are used to establish new capillary buds. Angiogenesis is tightly controlled through a balance between angiogenic (pro-angiogenic) and angiostatic (anti-angiogenic) factors. VEGF is considered to be the major angiogenic factor [97]. Activation of the vascular endothelial growth factor receptor 1 (VEGFR-1) and VEGFR-2 promotes endothelial cell proliferation and migration and exacerbates ECM degradation through different mechanisms including the PI3K/Akt and MEK/ERK protein kinase pathways [98]. NO, miRNAs, and Ang also have important roles in mediating angiogenesis. NO can increase the expression of VEGF in endothelial cells and increase vascular permeability in the ischemic brain. Ang can stabilize and remodel nascent blood vessels by binding to Tie-2 receptors. miR-210 and miR-140-5p modulate angiogenesis via upregulation of VEGFA expression, whereas it has been reported that miR-15a and miR-150 reduced vascular density in the infarct region in a rat model of MCAO [98].

Treadmill exercise has been demonstrated to promote angiogenesis in the infarct penumbra of animal brains, 


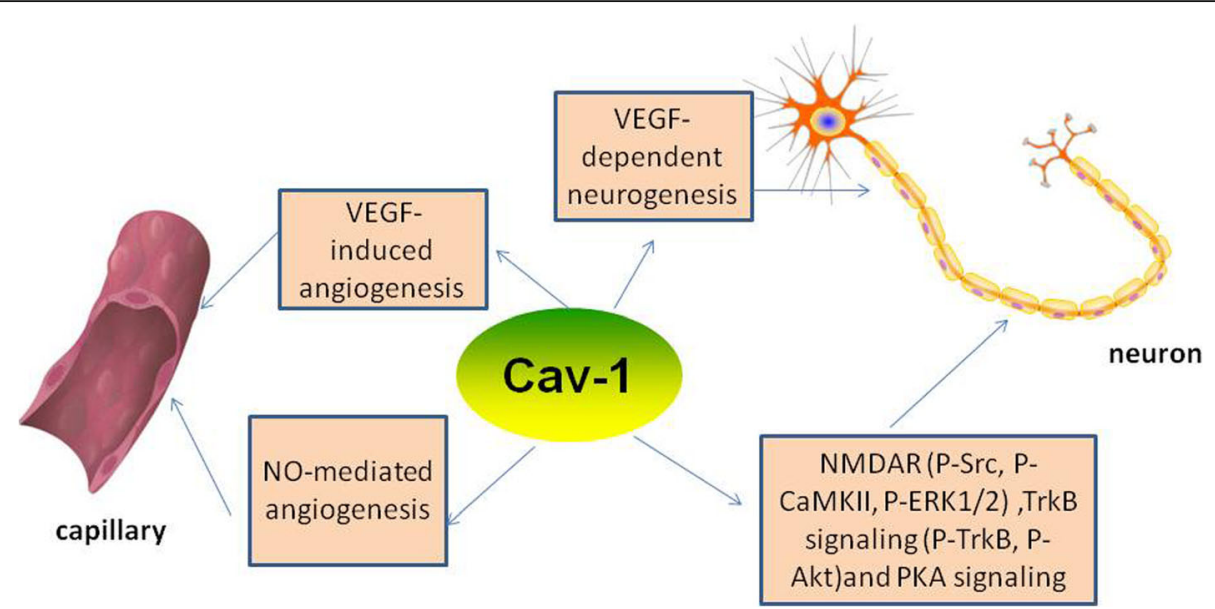

Fig. 2 The role of cav-1 in angiogenesis and neurogenesis. Cav-1 is essential for NO-mediated angiogenesis and VEGF-induced angiogenesis. VEGF can promote NO production and NO can increase the expression of VEGF. Cav-1/NEGF-dependent pathway is important for neurogenesis, and cav-1 enhances NMDAR (P-SrC, P-CaMKII, P-ERK1/2), TrkB signaling (P-TrkB, P-Akt), and PKA signaling, and augments dendritic growth and arborization. Methyl-D-aspartate receptor (NMDAR), calcium/calmodulin-dependent protein kinase II (CaMKII), phosphorylated (P)-extracellular signal-regulated kinase (ERK), tyrosine kinase B receptor (TrkB), CAMP-dependent protein kinase (PKA)

and an exercise group showed significantly higher expression of cav-1 and VEGF protein, better neurological recovery, and a smaller cerebral volume of infarction than a non-exercise group. And rats received the injection of the cav-1 inhibitor, daidzein, showed decreased expression of VEGF compared with the exercise group, which probably means that cav-1 pathway is involved in the regulation of VEGF after treadmill exercise [99]. Treatment using apigenin upregulated the expression of cav-1, VEGF, and eNOS compared with a control group, and cav-1 silencing counteracted apigenin-induced angiogenesis in vitro by promoting the tube formation ability of human umbilical vein endothelial cells (HUVECs) [100]. Genetic ablation of the cav-1 in mice resulted in impaired angiogenesis and increased apoptotic cell death in the ischemic brain. In vitro, adenoviral-mediated OE of caveolin-1 clearly accelerated endothelial cell differentiation/tubule formation and led to an upregulation in the number of capillary-like tubular structures. Conversely, knockdown of cav-1 using an antisense adenoviral gene delivery system reduced the number of capillary-like tubules, which demonstrates that cav- 1 plays a positive role in the regulation of endothelial cell differentiation [101]. These findings suggest that cav-1 may promote angiogenesis in IS. More specifically, in the process of angiogenesis, it appears that cav-1 negatively regulates endothelial cell proliferation and promotes cell differentiation [79]. Cav-1 inhibited endothelial cell proliferation by arresting cell cycle at the G0/G1 phase [102]. PD98059 is a specific inhibitor of mitogen-activated protein kinase and can suppress angiogenesis. PD98059 can also block decreases in cav-1 expression. Therefore, it is quite reasonable to consider that decreased cav-1 expression may play a significant role in the signaling required for endothelial cell proliferation [103].

Cav-1 has been shown to interact with certain angiogenic (pro-angiogenic) factors. Treatment of a HUVEC line (ECV 304) with some well-known angiogenic growth factors (VEGF, basic fibroblast growth factor, or hepatocyte growth factor/scatter factor) contributed to a dramatic reduction in cav-1 expression [103]. VEGFR-2 is localized in endothelial caveolae, and OE of cav-1 inhibits the activity of VEGFR-2 [104]. However, cav-1 also activates VEGFR-2 via a VEGF-dependent pathway, and the removal of caveolin and VEGFR-2 from caveolae leads to the inhibition of endothelial cell migration [104]. Re-expression of cav-1 in cav-1-deficient endothelial cells resulted in the relocation of VEGFR-2 in caveolar membranes and restored the VEGF-induced ERK and eNOS activation [105]. Cav-1 is also essential for NO-mediated angiogenesis. VEGF promotes the production of $\mathrm{NO}$ and the formation of capillary-like tubules. Antisense cav-1 oligonucleotides were transfected into HUVECs, and this resulted in a significant decrease in capillary-like tubules, and NO production did not respond to the addition of VEGF and NG-nitro-L-arginine methyl ester (L-NAME), a nonselective NOS inhibitor [106]. Although some angiogenic growth factors inhibit cav-1, cav-1 is important for VEGF or NO-mediated-angiogenesis. Cav-1 is a potential therapeutic target to improve angiogenesis for the treatment of stroke.

\section{Cav-1 and neurogenesis (Fig. 2)}

Similar to the angiogenic process, neurogenesis includes the proliferation, migration, and differentiation of neural 
stem cells (NSCs), which can differentiate into a variety of cells, including neurons, ependymal cells, astrocytes, and oligodendrocytes [107].

For instance, in neurogenesis in the olfactory bulb, initially, NSCs differentiate into neuroblasts, and then they migrate to the olfactory bulb and differentiate into periglomerular or granule neurons [108]. After stroke, if endogenous NSCs are not injured, NSCs will migrate to the ischemic region and differentiate into astrocytes [109]. Studies have demonstrated that adult NSCs in the subventricular zone (SVZ) of the lateral ventricle and the dentate gyrus of the hippocampus can be activated and produce neuroblasts which will recruit to the infarcted region and participate in repairing the ischemic brain tissue [110, 111]. The PI3K pathway, Wnt/beta-catenin pathway, the Notch pathway, and the Sonic Hedgehog pathway have been reported as affecting neurogenesis, as discussed in a review written by Koh and Park [107].

As mentioned earlier, treadmill exercise promotes angiogenesis in the infarcted penumbra via a cav-1/ VEGF-dependent pathway. Recently, a research group observed that the upregulation of both cav-1 and VEGF protein expression following treadmill exercise was consistent with improved recovery in neurological function which correlated with the proliferation, migration, and differentiation of SVZ-derived NSCs in the brain tissue. Furthermore, knockdown of cav-1 by a cav-1 inhibitor remarkably inhibited the treadmill exercise-induced upregulation in VEGF expression, improved neurological recovery, and decrease in the cerebral volume of infarction [112]. In addition, the cav-1/VEGF signaling pathway was found to play a role in basic fibroblast growth factor-induced angiogenesis and neurogenesis following treadmill exercise after acute IS [113]. This evidence suggests that cav-1 plays a positive role in neurogenesis. However, Li et al. found that in the hippocampal dentate gyrus (DG), cav-1 (-/-) mice displayed significantly higher levels of VEGF expression and more abundant formation of newborn neurons than cav-1 $(+/+)$ mice. Cav-1 peptide markedly inhibited neuronal differentiation [114]. It has been reported that cav-1 can regulate synaptic plasticity. Decreased expression of hippocampal caveolin-1 caused synaptic plasticity deficits in aged rats [115]. Cav-1 knockdown inhibited the morphine-induced upregulation of neurite outgrowth [116]. Neuron-targeted cav-1 overexpression enhanced dendritic arborization within the apical dendrites of hippocampal and granule cell neurons in adult and aged mice [117]. Similarly, Egawa et al. showed that neuron-targeted OE of cav-1 (SynCav1) promoted ultrastructural and functional hippocampal synaptic plasticity [118]. Head et al. showed that cav-1 OE, achieved using a synapsin-driven cav-1 vector, upregulated the formation of lipid rafts and the expression of neurotransmitter and neurotrophin receptors in primary neurons [119].
In conclusion, cav-1 promotes neurogenesis and neuroplasticity after ischemic stroke, but some studies demonstrate that cav-1 inhibits neural progenitor cells differentiation under normoxic and hypoxic conditions through the downregulation of VEGF signaling. One feasible explanation could be the paradox phenomenon between cav-1 and VEGF: cav-1 can downregulate VEGF, but is also essential for VEGF signaling. The relationship between cav-1 and VEGF signaling still needs further work. In neurons, pro-survival signals occur after the activation of various synaptic signaling receptors, including the $N$-methyl-D-aspartate (NMDA) glutamate receptor (NMDAR), the neurotrophin-activated tyrosine kinase B receptor (TrkB), and G-protein coupled receptors. These survival signals converge via intracellular protein kinases (CaMKII, Src, Akt, cAMP) to phosphorylate extracellular signal-regulated kinase 1/2 (ERK1/2), initiating the transcription of pro-survival and pro-growth genes. These receptors are distributed in regions enriched in caveolins. Cav-1 OE enhanced NMDAR (P-Src, P-CaMKII, P-ERK1/ 2) and TrkB signaling (P-TrkB, P-Akt) and augmented dendritic growth and arborization [120]. On glial cell line-derived neurotrophic factor stimulation, expression of cav-1 is increased in mesencephalic dopaminergic neurons, and modulation of genes which are correlated with neuronal plasticity and survival is mediated in part by ERK and cAMP-dependent protein kinase (PKA) signaling [121]. Increased p-ERK1/2 was almost diminished by the inhibition of caveolin and vice versa [120]. Therefore, cav-1 is essential for ERK activation and appears to be important in pro-survival signaling. Thus, cav-1 could be a novel therapeutic target protein for promoting neurogenesis after ischemic stroke.

\section{Cav-1 and neuroinflammation (Fig. 3)}

The role of caveolins in many aspects of the inflammatory response, including angiogenesis, leukocyte recruitment, pathogen invasion, the production of inflammatory mediators, and fibrosis, has been extensively demonstrated in the literature [122]. Severe BBB breakdown occurs several hours after ischemic attack and is followed by a massive infiltration of polymorphonuclear (PMN) leukocytes [123]. This event not only results in brain edema formation but also induces the activation of brain microglia which produce pro-inflammatory cytokines and ROS exacerbating the brain injury. Thus, we logically address that cav-1 inhibits inflammation via maintaining the integrity of BBB under brain ischemia condition. Niesman et al. illustrate that cav-1 regulates neuroinflammatory responses after traumatic brain injury (TBI), as cav-1 KO mice exhibited a significant increase in cytokine/chemokine production in a controlled cortical impact model of TBI [124]. Moreover, cavtratin, a cell permeable peptide of cav-1, has previously been shown to inhibit the 


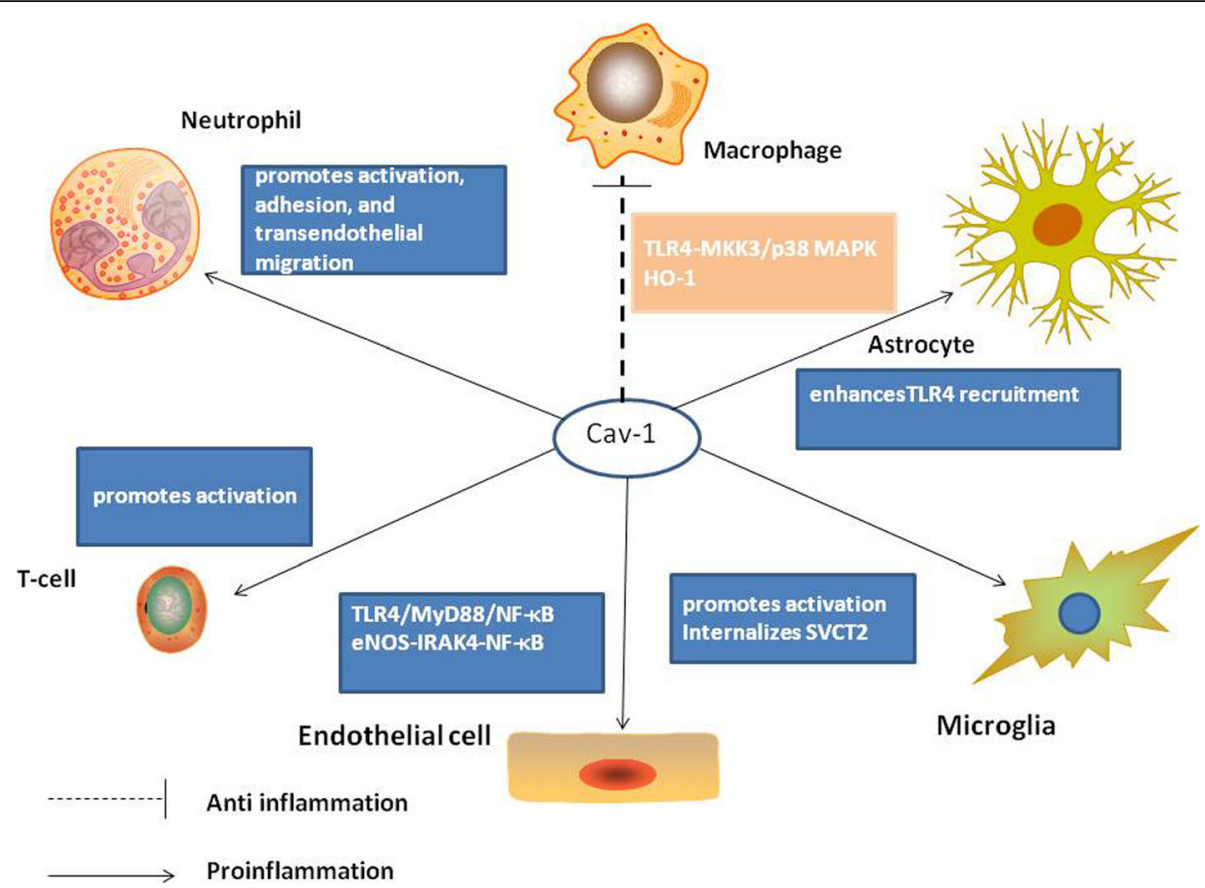

Fig. 3 Schematic illustrating the role of cav-1 in different cell. In endothelial cells, after exposure to LPS, cav-1 interacts with toll-like receptor 4 (TLR4), and then TLR4 promotes activation of MyD88, leading to NF-kB activation and the generation of proinflammatory cytokines. Under normal condition, cav-1 inhibits eNOS. If eNOS is activated, NO will nitrate IRAK4 which is a signaling factor required for NF-KB activation. And cav-1 in microglia can induce the internalization of SVCT2 which is the primary mediator of vitamin C uptake in neurons, triggering a proinflammatory phenotype in microglia and inducing microglia activation. Whereas in macrophages, cav-1decreases proinflammatory cytokine production and augments anti-inflammatory production through the TLR4/MKK3/p38 MAPK pathway. Besides, TLR4 activation by LPS also stimulates HO-1 transporting to the caveolae and producing CO which has anti-inflammatory effects and augments the cav-1/TLR4 interaction in murine macrophages. Toll-like receptor 4 (TLR4), interleukin-1 receptor associated kinase 4 (IRAK4), heme oxygenase-1 (HO-1), carbon oxide (CO), plasma membrane sodium-vitamin C cotransporter 2 (SVCT2)

transmigration and viability of macrophages and microglia via the JNK pathway and reduce inflammation in ocular neovascularization [125]. Cavtratin also reduces inflammatory cell infiltration, contributing to the improvement in BBB function in an immunologic mouse model of multiple sclerosis [126]. It is noteworthy that in healthy situation, cav-1 may as well inhibit inflammation, as systemic administration of cav-1 CSD to mice suppressed acute inflammation and vascular leak to the same extent as a glucocorticoid [127]. Caveolae have been reported as important in the internalization and later fate of several pathogens. For example, by targeting caveolae as an endocytic pathway, pathogens such as simian virus 40 and certain strains of Escherichia coli can be transported directly to the Golgi and/or ER, avoiding disruption in lysosomes and ensuring their intracellular survival [128]. However, cav-1 promotes the ability of macrophages to phagocytose both $E$. coli and apoptotic cells in vitro [129].

In the endothelium, after exposure to LPS, cav-1 was phosphorylated at $\operatorname{Tyr}(14)$ which resulted in interaction between cav-1 and toll-like receptor 4 (TLR4), and then TLR4 promoted activation of MyD88, leading to NF-kB activation and the generation of proinflammatory cytokines [130]. Cav-1 OE dose-dependently increased monocyte chemoattractant protein-1 (MCP-1), vascular cell adhesion molecule-1 (VCAM-1), and plasminogen activator inhibitor-1 (PAI-1) mRNA levels in human umbilical vein ECs. Pigment epithelium-derived factor binding to cav-1 could inhibit the pro-inflammatory effects of cav-1 in endothelial cells [131]. Cav-1 can affect NF- $\mathrm{kB}$ to influence the inflammatory response. Signaling by the proinflammatory cytokine interleukin-1 $\beta$ (IL-1 $\beta$ ) is dependent on ROS, because after IL- $1 \beta$ binding to its receptor (IL-1R1), ROS generated by Nox2 is responsible for the downstream recruitment of IL-1R1 effectors (IRAK, TRAF6, IkappaB kinase kinases) and ultimately for activation of NF-kB. Lipid rafts and cav-1 coordinate IL-1 $\beta$-dependent activation of NF- $\mathrm{kB}$. Inhibiting cav-1-mediated endocytosis can prevent NF- $\mathrm{KB}$ activation [132]. Cav-1 gene KO lungs displayed suppression of $\mathrm{NF}-\mathrm{kB}$ activity and reduced transcription of iNOS and intercellular adhesion molecule 1 (ICAM-1) [133]. Secondary to the loss of cav-1, eNOS is activated, which inhibits the innate immune response to LPS through interleukin-1 receptor-associated kinase 4 (IRAK4) nitration. IRAK4 is a signaling factor required for NF- $k B$ 
activation and innate immunity. Cav-1 $\mathrm{KO}$ can impair the activity of NF- $\mathrm{KB}$ and reduce LPS-induced lung injury [134]. Cav-1 appears to have different roles in different cells. In macrophages, the interaction of cav-1 with TLR4 has an opposite outcome compared with that in endothelium, whereby overexpression of cav-1 decreased LPS-induced TNF- $\alpha$ and IL- 6 proinflammatory cytokine production and augmented anti-inflammatory cytokine IL-10 production. Cav-1 regulates LPS-induced inflammatory cytokine production through the MKK3/p38 MAPK pathway [135]. It is valuable to mention that TLR4 activation by LPS also stimulates heme oxygenase-1 (HO-1) transporting to the caveolae by a p38 MAPK-dependent mechanism and producing carbon oxide $(\mathrm{CO})$. $\mathrm{CO}$ has anti-inflammatory effects and augments the cav-1/TLR4 interaction in murine macrophages [136]. In PMN leukocytes, cav-1 appears to promote activation, adhesion, and transendothelial migration and shows a positive role in PMN activation-induced lung and vascular injury [137]. Cav-1 also plays a key role in antigen-presenting cells, leading to the activation of $\mathrm{T}$ lymphocytes [138]. Furthermore, apoptosis of thymocytes in cav-1-deficient mice was higher than that in wild type mice, indicating that cav-1 is a key regulator of thymocyte apoptosis during inflammation [139]. In addition, cav-1 has a possible role in microglial activation. Cav-1 was remarkably reduced and localized in the plasmalemma and cytoplasmic vesicles of inactive microglia, whereas active (amoeboid-shaped) microglia exhibited increased cav-1 expression [46]. Recently, Portugal et al. found that cav-1 in microglia induced the internalization of plasma membrane sodium-vitamin C cotransporter 2 (SVCT2), triggering a proinflammatory phenotype in microglia and inducing microglia activation [140]. Besides, cav-1 transfection into Fatty acid-binding proteins-KO astrocytes remarkably enhanced TLR4 recruitment into lipid raft and tumor necrosis factor-a production after LPS stimulation [141]. Together, in non-pathological states or after LPS stimulation, cav-1 in endothelial cells increases proinflammatory cytokines, while cav-1 inhibits LPS-induced inflammatory effects in murine macrophages. Cav-1 is involved in activation of microglia, PMN, and T lymphocytes.

Apart from the LPS-eNOS-TLR4-NFкB, MKK3/p38 MAPK, and IL-1 $\beta-I L-1 R 1$ pathways which we have already mentioned, cav-1 participates in additional inflammatory signaling pathways [142]. Cyclooxygenase (COX)-2 is pivotal in post-ischemic brain damage, and the selective inhibition of the COX-2 enzyme inhibited subsequent prostaglandin E2 (PGE2) production, ischemic BBB leakage, leukocyte infiltration, and edema formation [143]. In cav-1-null mice, COX-2 protein levels are higher. Cav-1 binds COX-2 in the endoplasmic reticulum (ER) and modulates its degradation through an ER-dependent mechanism [144]. This suggests that cav-1 can regulate inflammatory responses by controlling COX-2 expression.

\section{Cav-1 and apoptosis}

Apoptosis is morphologically characterized by a programmed cell death [145]. However, necrosis is a process of physico-chemical cell destruction and involves cellular plasma membrane disruption [146]. Autophagy is mainly triggered by cell starvation, and cells orchestrate self-digestion of long-lived proteins and damaged organelles in the lysosome. Autophagy might principally serve for cell survival, but sometimes leads to cell death [147]. Apoptosis is a highly conserved cellular response to cellular stress, DNA-, or organelle damage, but also plays a crucial role in the removal of superfluous cells. The destruction of one cell can be beneficial: the removal of superfluous cells is necessary for the development of functioning organs, and the removal of injured or aged cells that have lost their function can help to maintain tissue vitality [148]. Apoptosis can be initiated via two main routes: the extrinsic and intrinsic pathways. The intrinsic apoptotic pathway is usually triggered by stimuli, including DNA damage, organelle dysfunction of either mitochondria or the ER, the accumulation of unfolded proteins, growth factor withdrawal, or hyperthermia. The extrinsic pathway is triggered when ligands bind their trans-membrane death receptors. The extrinsic pathway not only directly leads to the activation of proteases which cause cell death, but also promotes the release of pro-apoptotic factors from mitochondria, which are linked with the intrinsic pathway [148].

Caveolins are directly connected with both the intrinsic and extrinsic cell death pathways. The key to the extrinsic pathway is the expression of transmembrane receptors, called death receptors, including TNF-receptor 1, Fas/CD95, and the TNF-related apoptosis-inducing ligand receptors. A potential cav-1 binding motif (G53LHHDGQFCH) has been identified in the human death receptor Fas sequence [149]. Cav-1 KO disrupted death-induced signaling complex formation following colocalization and interaction between cav-1 and Fas [150]. Recently, Glukhova et al. found that the deletion of both caveolin-binding sites (which bind the $\mathrm{N}$-terminal domain and B-terminal domain of cav-1) in the Fas-ligand attenuated extrinsic cell death pathway-associated cytotoxicity, demonstrating that the relationship between the Fas-ligand and cav-1 provides a molecular basis for the location of the ligand to lipid rafts and Fas-ligand-dependent apoptosis [151]. As for the intrinsic apoptosis pathway, mitochondrial outer membrane permeabilization is the central event of the intrinsic pathway: in response to apoptotic stimuli, mitochondria release intermembrane space proteins, such as cytochrome $\mathrm{C}$ and apoptosis-inducing factor, which exert a cryptic cytotoxic activity following their mitochondrial 
release [152]. And mitochondrial dysfunction is considered as a hallmark of intrinsic apoptosis. In E11 podocytes, cav-1 OE attenuated $\mathrm{H}_{2} \mathrm{O}_{2}$-induced oxidative stress responses and preserved mitochondrial function, as well as significantly suppressing apoptosis [153]. Moreover, various cav-1-deficient cells have displayed mitochondrial dysfunction including impaired energy generation, and increased mitochondrial ROS production [154-156]. Based on the abovementioned findings, we speculate that cav-1 could relay apoptotic signaling via allowing Fas multimerization, but also attenuates apoptosis through preventing mitochondrial dysfunction.

Additionally, cav-1 plays a different role in regulating apoptosis in different cell types. In HEK293T cells, cav-1 was shown to reduce survivin, which inhibits apoptosis through a pathway involving diminished beta-catenin-Tcf/ Lef-dependent transcription. This suggests that cav-1 has pro-apoptotic properties [157]. However, there is also evidence to suggest that cav-1 suppresses apoptosis. In hypoxic human SK-N-MC neuroblastoma cells, iNOS-induced NO production reduces the expression of cav-1. OE of cav-1, either through cav-1 transfection or administration of a cav-1 CSD peptide, decreased the production of NO and impaired apoptotic cell death in hypoxic SK-N-MC cells [158]. Yue et al. demonstrated that cav-1 could suppress ER stress-induced macrophage apoptosis in vitro, and one of the underlying mechanisms may be associated with the activation of the p38 MAPK pro-survival pathway [159]. Cav-1 KO macrophages were more susceptible to apoptosis and more prone to induce inflammation than wild-type macrophages. Decreased cav-1 protein levels mediated I/R injury-induced liver damage by inhibiting sphingosine kinase 2/sphingosine-1-phosphate receptor 2 signaling and enhancing apoptosis [160].

The anti-apoptotic role of cav- 1 in ischemic stroke is suggested by Jasmin et al.; they showed increased apoptotic cell death in cav-1 KO ischemic brains, as compared with WT ischemic brains. But the underlying mechanisms are still not clear. Recently, it was found that downregulation of cav-1 using cav-1 small interfering RNA remarkably worsened astrocyte cell damage, while overexpression of cav-1 using a cav-1 CSD peptide attenuated OGD-induced cell apoptosis via Ras/Raf/ERK pathway [161]. This may partly explain why cav-1 inhibits apoptosis in IS.

\section{Cav-1 and free radicals (Fig. 4)}

As discussed in previous sections, ROS and RNS play important roles in IS. Cav-1 has been shown to reduce ROS production in endothelial cells. Mitochondrial ROS production was increased in endothelial cells following cav-1 knockdown. Chen et al. observed that cav-1 inhibited the activity of NADPH oxidases, a major source of cellular ROS [162]. Cav-1-targeted treatments could scavenge reactive species in cancer cells [163]. Src homology 2-containing protein tyrosine phosphatase 2 (SHP-2)

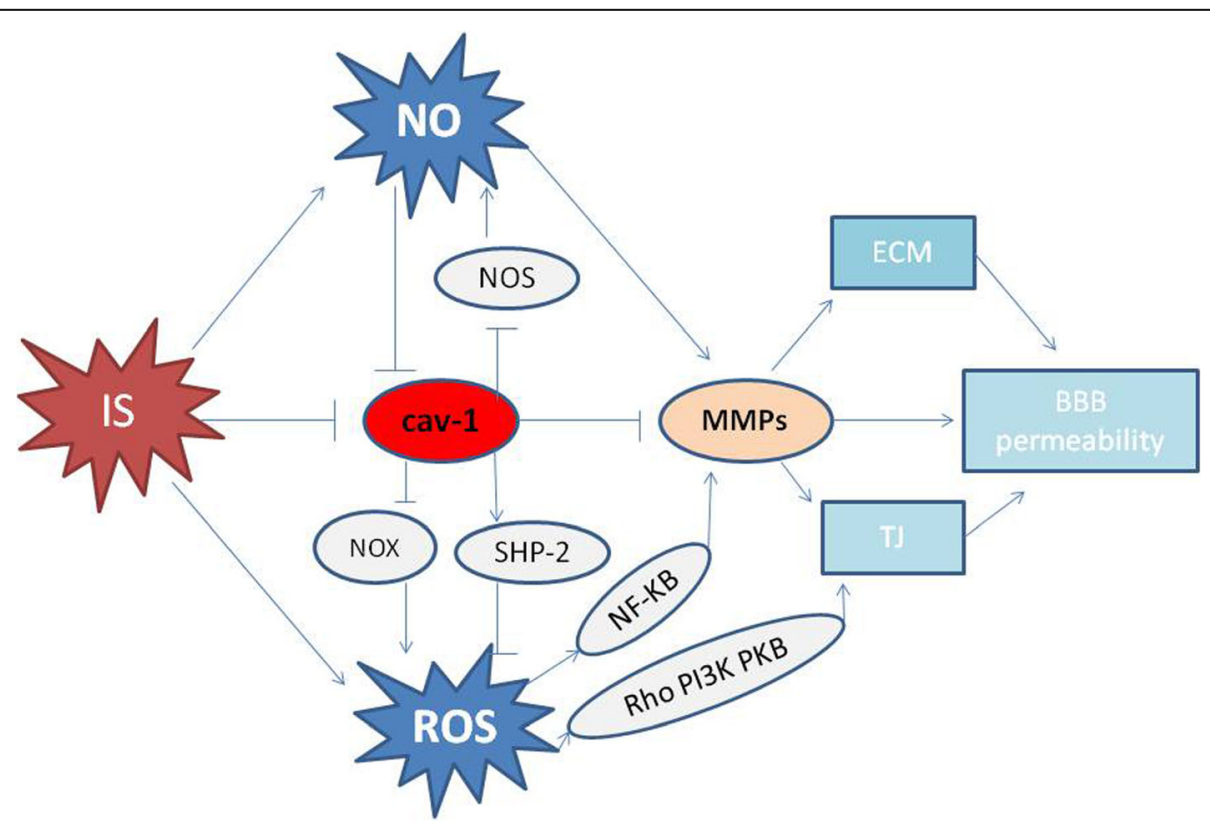

Fig. 4 Relationship between cav-1 and free radicals. On one hand, cav-1 directly binds to NOS and decreases NO; on the other hand, NO negatively regulates cav-1 expression. Cav-1 reduces the production of ROS via inhibiting the activity of NADPH oxidases (NOX) and (or) promoting SHP-2 activation. NO and ROS can activate MMP-2 and MMP-9, disrupting TJ and ECM, finally inducing BBB hyperpermeability. Thus, cav-1 can inhibit the activity of MMP2 and MMP9 through reducing NO and ROS. Ischemic stroke (IS), NADPH oxidases (NOX), Src homology 2-containing protein tyrosine phosphatase 2 (SHP-2) 
provided neuroprotection in a stroke model. Cav-1 protected astrocytes from ROS-induced oxidative stress via SHP-2 activation [164]. According to the aforementioned findings that ROS can induce and/or activate MMPs, we propose that cav-1 protects the BBB from disruption by reduction of ROS and inhibition of MMPs activity.

NO can inhibit the expression of cav-1, but cav-1 can inhibit NO production through binding with $\mathrm{NO}$ synthase (NOS) and inhibition of cav-1 promotes the activation of NOS and increases NO levels. Glutathione S-transferase (GST) pull-down using purified proteins confirmed that direct binding of cav-1 and NOS occurred between residues 82-101 [165] and that F92 is the key residue to mediate endothelial NO synthase (eNOS) inhibition by cav-1 [166]. High NO concentrations decrease cav-1 abundance and alter its cellular distribution in endothelial cells [167]. NO decreased the expression of cav-1 after IS, and NOS inhibitors prevented the loss of cav-1 in the core and penumbra of the ischemic brain [168]. It is interesting to note that positive regulation of cav- 1 by $\mathrm{NO}$ is found in tumor cells. The NO donor diethylenetriamine (DETA)/NO upregulated cav-1 in hypoxic human SK-N-MC neuroblastoma cells [33]. Thus, the role of NO in the modulation of cav-1 expression appears to be different in different cell types. Incubation of pure eNOS with peptides derived from the CSD of cav-1 and cav-3 led to inhibition of eNOS, inducible NO synthase (iNOS), and neuronal NO synthase (nNOS) activity [169]. And overexpression of caveolin markedly decreased eNOS enzyme activity in endothelial cells [170]. In addition, delivery of the cav-1 CSD inhibited NO synthesis and inflammation [127]. Loss of cav-1 leads to persistent eNOS activation and high levels of $\mathrm{NO}$ in cells, through the loss of cav-1 inhibitory effects on eNOS [171]. It has also been shown that pharmacological blockade or genetic deletion of eNOS prevents many of the physiological changes observed in cav-1 KO mice [172]. Based on the literature, it seems that the interaction of cav-1 and NO partly explains why cav-1 protects BBB integrity from IS. Cav-1 KO mice had increased eNOS activity and NO production; subsequently, NO production directly contributed to MMP activation and BBB disruption. L-NAME preserved the expression of cav-1, inhibited MMPs activity, and reduced BBB permeability.

\section{Conclusion (Fig. 5)}

IS is a major cause of death and long-lasting disability worldwide. In this review, we have introduced several major pathophysiological mechanisms in IS, such as BBB damage, inflammation, and free radicals, and summarized the role of T cells in IS. In addition, we discussed evidence

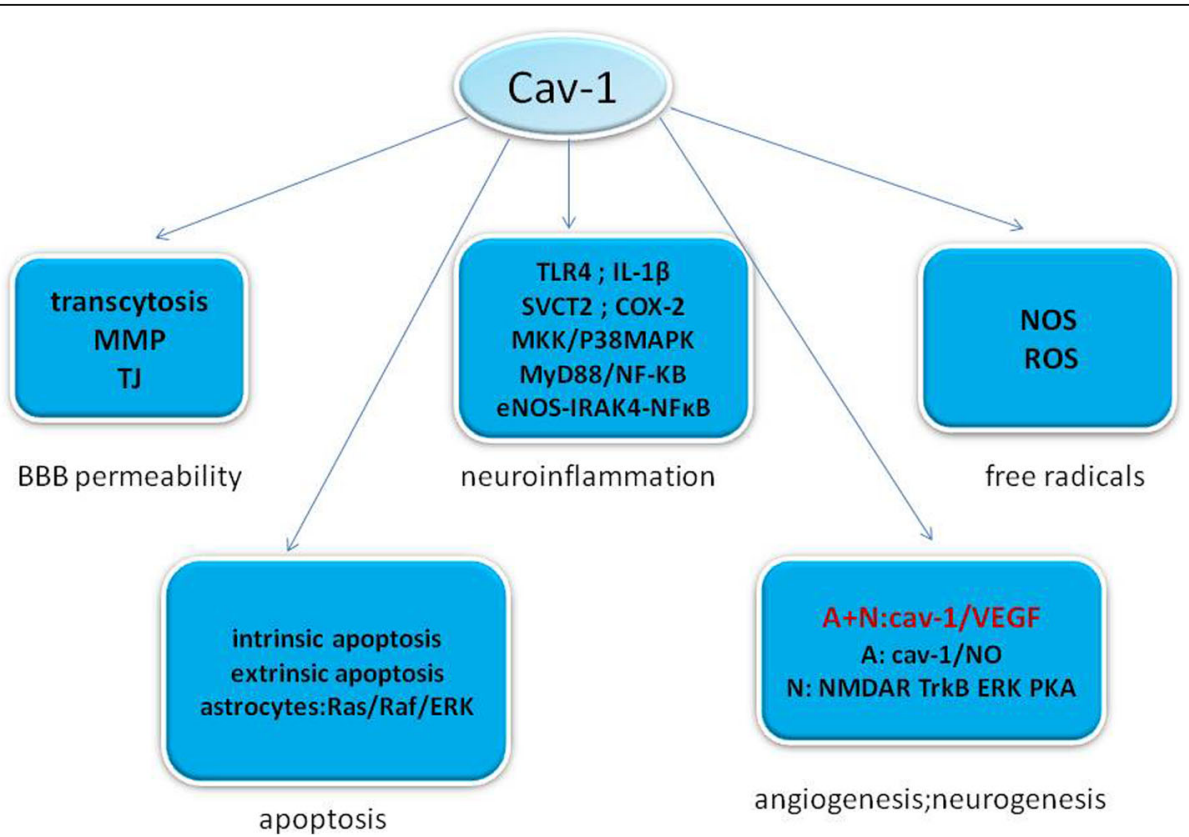

Fig. 5 Schematic representation illustrating the role of caveolin-1 in regulating BBB permeability, neuroinflammantion, free radicals, apoptosis, angiogenesis, and neurogenesis and showing some of the signaling pathways coupling caveolae/caveolins with IS. Changing BBB permeability via transcytosis, MMP, and TJ; regulating neuroinflammantion via TLR4, IL-1ß, SVCT2, COX2, MKK/P38MAPK, MyD88/NF-KB, and eNOS-IRAK4-NFKB pathway; altering free radicals via reducing NOS and ROS; influencing apoptosis through intrinsic apoptotic pathway and extrinsic apoptotic pathway and protecting astrocytes from apoptosis via Ras/Raf/ERK pathway; promoting angiogenesis through cav-1/NEGF and cav-1/NO pathway; and promoting neurogenesis via cav-1NEGF pathway and neuroplasticity through NMDAR, TrkB, ERK, and PKA pathway. Interleukin-1 $\beta$ (IL-1 $\beta$ ), cyclooxygenase-2 (COX-2), mitogen-activated protein kinase (MAPK), reactive nitrogen species (RNS), reactive oxygen species (ROS), extracellular signal-regulated kinase (ERK), vascular endothelial growth factor (VEGF), N-methyl-D-aspartate receptor (NMDAR) 
that cav-1 may serve to promote neuroprotection after stroke and also listed some opposing results. Cav-1 OE decreases brain edema in a rat MCAO model, and cav-1 $\mathrm{KO}$ increases brain infarction volume. However, some natural active compounds, such as green tea polyphenols, show a protective role in brain ischemia which is correlated with a decrease in cav-1. In angiogenesis, cav-1 negatively regulates endothelial cell proliferation, while promoting differentiation. Cav-1 is necessary for VEGFR-2 to undergo VEGF-dependent activation, but $\mathrm{OE}$ of cav-1 inhibits VEGFR-2 activity. As for neurogenesis, treadmill exercise-mediated improved neurological recovery is significantly inhibited when cav- 1 is reduced. Cav-1 also enhances pro-survival signaling (NMDAR, TrkB, ERK signaling) and promotes dendritic growth and arborization. It is worth noting that in the hippocampal DG, cav-1 KO mice showed more newborn neurons than the wild-type mice. Cav-1 plays a pro-inflammatory role in endothelial cells, neutrophils, lymphocytes, and microglia, but has an opposing role in macrophages. Cav-1 connects with both the intrinsic and extrinsic apoptotic pathways. Interaction of Fas-ligand and cav-1 provides a molecular basis for the induction of Fas-ligand-dependent cell death. Cav-1 exerts anti-apoptotic action in the intrinsic apoptotic pathway. Using different cell or animal models may help to fully elucidate the role of cav-1 in IS, and we should explore more to answer the controversy.

\begin{abstract}
Abbreviations
BBB: Blood-brain barrier; BMECs: Brain microvascular endothelial cells; BTB: Blood-tumor barrier; Cav: Caveolin; CBD: Caveolin-binding motifs; CO: Carbon oxide; COX-2: Cyclooxygenase-2; CSD: Caveolin scaffolding domain; DG: Dentate gyrus; ECM: Extracellular matrix; eNOS: Endothelial NO synthase; ER: Endoplasmic reticulum; ERK: Extracellular signal-regulated kinase; $\mathrm{H}_{2} \mathrm{O}_{2}$ : Hydrogen peroxide; $\mathrm{HO}-1$ : Heme oxygenase-1; ICAM1: Intercellular adhesion molecule 1; IL-1: Interleukin-1; iNOS: Inducible NO synthase; IS: Ischemic stroke; KO: Knockout; L-NAME: NG-nitro-L-arginine methyl ester; LPS: Lipopolysaccharide; MCAO: Middle cerebral artery occlusion; MCP-1: Monocyte chemoattractant protein-1; MMPs: Matrix metalloproteases; NMDAR: N-methyl-D-aspartate receptor; nNOS: neuronal NO synthase; NSCs: Neural stem cells; OE: Overexpression; OGD: Oxygenglucose deprivation; PAl-1: Plasminogen activator inhibitor-1; PKA: CAMPdependent protein kinase; PMN: Polymorphonuclear; RNS: Reactive nitrogen species; ROS: Reactive oxygen species; sHT: Symptomatic hemorrhagic transformation; SVCT2: Plasma membrane sodium-vitamin C cotransporter 2; SVZ: Subventricular zone; TBI: Traumatic brain injury; Tc: Cytotoxic T cells/CD8 + T cells; Th: Helper T cells/CD4+T cells; TJs: Tight junctions; tPA: Tissue plasminogen activator; Tregs: Regulatory cells; TrkB: Tyrosine kinase B receptor; VCAM-1: Vascular cell adhesion molecule-1; VEGF: Vascular endothelial growth factor; VEGFR: Vascular endothelial growth factor receptor
\end{abstract}

\section{Acknowledgements}

Not applicable

\section{Funding}

This work was supported by the National Natural Science Foundation of China (Grant no. 81271298).

Availability of data and materials

Not applicable

\section{Authors' contributions}

This work was primarily written by $\mathrm{QH}$. WZ contributed to the acquisition or analysis of literature for the work. Figures were produced by $\mathrm{ZH}$ and $\mathrm{QH}$. $\mathrm{ZH}$ also contributed to editing the review. XT supervised the work, helped with summarizing the paper, and contributed to the review revision. All authors read and approved the final manuscript.

Ethics approval and consent to participate

Not applicable

\section{Consent for publication}

Not applicable

\section{Competing interests}

The authors declare that they have no competing interests.

\section{Publisher's Note}

Springer Nature remains neutral with regard to jurisdictional claims in published maps and institutional affiliations.

Received: 10 September 2018 Accepted: 29 November 2018

Published online: 20 December 2018

\section{References}

1. Benjamin EJ, Virani SS, Callaway CW, Chamberlain AM, Chang AR, Cheng S, Chiuve SE, Cushman M, Delling FN, Deo R, et al. Heart disease and stroke statistics-2018 update: a report from the American Heart Association. Circulation. 2018;137:e67-e492

2. Lakhan SE, Kirchgessner A, Tepper D, Leonard A. Matrix metalloproteinases and blood-brain barrier disruption in acute ischemic stroke. Front Neurol. 2013;4:32

3. Dirnagl U, ladecola C, Moskowitz MA. Pathobiology of ischaemic stroke: an integrated view. Trends Neurosci. 1999;22:391-7.

4. Allen $\mathrm{CL}$, Bayraktutan U. Oxidative stress and its role in the pathogenesis of ischaemic stroke. Int J Stroke. 2009:4:461-70.

5. Powers WJ, Rabinstein AA, Ackerson T, Adeoye OM, Bambakidis NC, Becker K, Biller J, Brown M, Demaerschalk BM, Hoh B, et al. Guidelines for the early management of patients with acute ischemic stroke: a guideline for healthcare professionals from the American Heart Association/American Stroke Association. Stroke. 2018;2018(49):e46-e110.

6. Henderson SJ, Weitz Jl, Kim PY. Fibrinolysis: strategies to enhance the treatment of acute ischemic stroke. J Thromb Haemost. 2018;16:1932-40.

7. Echarri A, Del Pozo MA. Caveolae. Curr Biol. 2012;22:R114-6.

8. Nag S, Kapadia A, Stewart DJ. Review: molecular pathogenesis of bloodbrain barrier breakdown in acute brain injury. Neuropathol Appl Neurobiol. 2011;37:3-23.

9. Anderson RG. The caveolae membrane system. Annu Rev Biochem. 1998;67: 199-225.

10. Liu P, Rudick M, Anderson RGW. Multiple functions of caveolin-1. J Biol Chem. 2002;277:41295-8

11. Sims NR. Calcium, energy metabolism and the development of selective neuronal loss following short-term cerebral ischemia. Metab Brain Dis. 1995; 10:191-217

12. Deb P, Sharma S, Hassan KM. Pathophysiologic mechanisms of acute ischemic stroke: an overview with emphasis on therapeutic significance beyond thrombolysis. Pathophysiology. 2010;17:197-218.

13. Wang S, Head BP. Caveolin-1 in stroke neuropathology and neuroprotection: a novel molecular therapeutic target for ischemic-related injury. Curr Vasc Pharmacol. 2019;17:41-49.

14. Kuroiwa T, Ting P, Martinez $\mathrm{H}$, Klatzo I. The biphasic opening of the bloodbrain barrier to proteins following temporary middle cerebral artery occlusion. Acta Neuropathol. 1985;68(2):122-9.

15. Rosenberg GA. Neurological diseases in relation to the blood-brain barrier. J Cereb Blood Flow Metab. 2012:32:1139-51.

16. Klein T, Bischoff R. Physiology and pathophysiology of matrix metalloproteases. Amino Acids. 2011:41:271-90.

17. Rosenberg GA, Kornfeld M, Estrada E, Kelley RO, Liotta LA, Stetler-Stevenson WG. TIMP-2 reduces proteolytic opening of blood-brain barrier by type IV collagenase. Brain Res. 1992;576:203-7. 
18. Asahi M, Sumii T, Fini ME, Itohara S, Lo EH. Matrix metalloproteinase 2 gene knockout has no effect on acute brain injury after focal ischemia. Neuroreport. 2001;12:3003-7.

19. Asahi M, Asahi K, Jung JC, del Zoppo GJ, Fini ME, Lo EH. Role for matrix metalloproteinase 9 after focal cerebral ischemia: effects of gene knockout and enzyme inhibition with BB-94. J Cereb Blood Flow Metab. 2000;20: 1681-9.

20. Bazzoni G, Dejana E. Endothelial cell-to-cell junctions: molecular organization and role in vascular homeostasis. Physiol Rev. 2004;84:869-901.

21. Wang $Q$, Doerschuk CM. The signaling pathways induced by neutrophilendothelial cell adhesion. Antioxid Redox Signal. 2002;4:39-47.

22. Jin R, Yang G, Li G. Inflammatory mechanisms in ischemic stroke: role of inflammatory cells. J Leukoc Biol. 2010;87:779-89.

23. Gelderblom M, Leypoldt F, Steinbach K, Behrens D, Choe C, Siler DA, Arumugam TV, Orthey E, Gerloff C, Tolosa E, Magnus T. Temporal and spatial dynamics of cerebral immune cell accumulation in stroke. Stroke. 2009;40:1849-57.

24. Jiang X, Andjelkovic AV, Zhu L, Yang T, Bennett MVL, Chen J, Keep RF, Shi Y. Blood-brain barrier dysfunction and recovery after ischemic stroke. Prog Neurobiol. 2018;163-164:144-71.

25. Gidday JM, Gasche YG, Copin J, Shah AR, Perez RS, Shapiro SD, Chan PH, Park TS. Leukocyte-derived matrix metalloproteinase-9 mediates blood-brain barrier breakdown and is proinflammatory after transient focal cerebral ischemia. Am J Physiol Heart Circ Physiol. 2005;289:H558-68.

26. Yilmaz G, Arumugam TV, Stokes KY, Granger DN. Role of T lymphocytes and interferon-gamma in ischemic stroke. Circulation. 2006;113:2105-12.

27. Gu L, Jian Z, Stary C, Xiong X. T cells and cerebral ischemic stroke. Neurochem Res. 2015;40:1786-91.

28. Liesz A, Suri-Payer E, Veltkamp C, Doerr H, Sommer C, Rivest S, Giese T, Veltkamp R. Regulatory T cells are key cerebroprotective immunomodulators in acute experimental stroke. Nat Med. 2009;15:192-9.

29. Kleinschnitz C, Kraft P, Dreykluft A, Hagedorn I, Gobel K, Schuhmann MK, Langhauser F, Helluy X, Schwarz T, Bittner S, et al. Regulatory T cells are strong promoters of acute ischemic stroke in mice by inducing dysfunction of the cerebral microvasculature. Blood. 2013;121:679-91.

30. Offner H, Hurn PD. A novel hypothesis: regulatory B lymphocytes shape outcome from experimental stroke. Transl Stroke Res. 2012;3:324-30.

31. Rodrigo R, Fernandez-Gajardo R, Gutierrez R, Matamala JM, Carrasco R, Miranda-Merchak A, Feuerhake W. Oxidative stress and pathophysiology of ischemic stroke: novel therapeutic opportunities. CNS Neurol Disord Drug Targets. 2013;12:698-714.

32. Emerich DF, Dean RLR, Bartus RT. The role of leukocytes following cerebral ischemia: pathogenic variable or bystander reaction to emerging infarct? Exp Neurol. 2002;173:168-81.

33. Gu Y, Dee CM, Shen J. Interaction of free radicals, matrix metalloproteinases and caveolin-1 impacts blood-brain barrier permeability. Front Biosci (Schol Ed). 2011;3:1216-31.

34. Shinohara M, Adachi Y, Mitsushita J, Kuwabara M, Nagasawa A, Harada S, Furuta S, Zhang Y, Seheli K, Miyazaki H, Kamata T. Reactive oxygen generated by NADPH oxidase 1 (Nox1) contributes to cell invasion by regulating matrix metalloprotease-9 production and cell migration. J Biol Chem. 2010;285:4481-8.

35. Schreibelt G, Kooij G, Reijerkerk A, van Doorn R, Gringhuis SI, van der Pol S, Weksler BB, Romero IA, Couraud P, Piontek J, et al. Reactive oxygen species alter brain endothelial tight junction dynamics via RhoA, PI3 kinase, and PKB signaling. FASEB J. 2007;21:3666-76.

36. Lundberg JO, Weitzberg E, Gladwin MT. The nitrate-nitrite-nitric oxide pathway in physiology and therapeutics. Nat Rev Drug Discov. 2008;7: 156-67.

37. Kiss JP, Vizi ES. Nitric oxide: a novel link between synaptic and nonsynaptic transmission. Trends Neurosci. 2001;24:211-5.

38. Murphy S, Gibson CL. Nitric oxide, ischaemia and brain inflammation. Biochem Soc T. 2007;35:1133-7

39. Matsui T, Nagafuji T, Kumanishi T, Asano T. Role of nitric oxide in pathogenesis underlying ischemic cerebral damage. Cell Mol Neurobiol. 1999:19:177-89

40. Chen H, Chen X, Li W, Shen J. Targeting RNS/caveolin-1/MMP signaling cascades to protect against cerebral ischemia-reperfusion injuries: potential application for drug discovery. Acta Pharmacol Sin. 2018;39:669-82.

41. Yamada $E$. The fine structure of the gall bladder epithelium of the mouse. J Biophys Biochem Cytol. 1955;1:445-58.
42. Busija AR, Patel HH, Insel PA. Caveolins and cavins in the trafficking, maturation, and degradation of caveolae: implications for cell physiology. Am J Physiol Cell Physiol. 2017;312:C459-77.

43. Arbuzova A, Wang L, Wang J, Hangyas-Mihalyne G, Murray D, Honig B, McLaughlin S. Membrane binding of peptides containing both basic and aromatic residues. Experimental studies with peptides corresponding to the scaffolding region of caveolin and the effector region of MARCKS. Biochemistry-Us. 2000;39:10330-9.

44. Schlegel A, Lisanti MP. A molecular dissection of caveolin-1 membrane attachment and oligomerization. Two separate regions of the caveolin-1 Cterminal domain mediate membrane binding and oligomer/oligomer interactions in vivo. J Biol Chem. 2000;275:21605-17.

45. Shin T, Kim H, Jin J, Moon C, Ahn M, Tanuma N, Matsumoto Y. Expression of caveolin-1, -2 , and -3 in the spinal cords of Lewis rats with experimental autoimmune encephalomyelitis. J Neuroimmunol. 2005;165(1-2):11-20. https://doi.org/10.1016/j.jneuroim.2005.03.019.

46. Niesman IR, Zemke N, Fridolfsson HN, Haushalter KJ, Levy K, Grove A, Schnoor R, Finley JC, Patel PM, Roth DM, et al. Caveolin isoform switching as a molecular, structural, and metabolic regulator of microglia. Mol Cell Neurosci. 2013;56:283-97.

47. Ikezu T, Ueda H, Trapp BD, Nishiyama K, Sha JF, Volonte D, Galbiati F, Byrd $A L$, Bassell G, Serizawa $H$, et al. Affinity-purification and characterization of caveolins from the brain: differential expression of caveolin-1, -2 , and -3 in brain endothelial and astroglial cell types. Brain Res. 1998;804:177-92.

48. Virgintino D, Robertson D, Errede M, Benagiano V, Tauer U, Roncali L, Bertossi M. Expression of caveolin-1 in human brain microvessels. Neuroscience. 2002;115:145-52.

49. Tang Z, Scherer PE, Okamoto T, Song K, Chu C, Kohtz DS, Nishimoto I, Lodish HF, Lisanti MP. Molecular cloning of caveolin-3, a novel member of the caveolin gene family expressed predominantly in muscle. J Biol Chem. 1996;271(4):2255-61.

50. Scherer PE, Okamoto T, Chun M, Nishimoto I, Lodish HF, Lisanti MP. Identification, sequence, and expression of caveolin-2 defines a caveolin gene family. Proc Natl Acad Sci U S A. 1996;93(1):131-5.

51. Razani B, Wang XB, Engelman JA, Battista M, Lagaud G, Zhang XL, Kneitz B, Hou HJ, Christ GJ, Edelmann W, Lisanti MP. Caveolin-2-deficient mice show evidence of severe pulmonary dysfunction without disruption of caveolae. Mol Cell Biol. 2002;22:2329-44.

52. Gazzerro E, Sotgia F, Bruno C, Lisanti MP, Minetti C. Caveolinopathies: from the biology of caveolin-3 to human diseases. Eur J Hum Genet. 2010;18: 137-45.

53. Couet J, Li S, Okamoto T, Ikezu T, Lisanti MP. Identification of peptide and protein ligands for the caveolin-scaffolding domain. Implications for the interaction of caveolin with caveolae-associated proteins. J Biol Chem. 1997; 272:6525-33.

54. Okamoto T, Schlegel A, Scherer PE, Lisanti MP. Caveolins, a family of scaffolding proteins for organizing "preassembled signaling complexes" at the plasma membrane. J Biol Chem. 1998;273:5419-22.

55. Yamamoto M, Toya Y, Schwencke C, Lisanti MP, Myers MGJ, Ishikawa Y. Caveolin is an activator of insulin receptor signaling. J Biol Chem. 1998;273: 26962-8.

56. Pelkmans L. Secrets of caveolae- and lipid raft-mediated endocytosis revealed by mammalian viruses. Biochim Biophys Acta. 2005;1746:295-304.

57. Gargalovic P, Dory L. Cellular apoptosis is associated with increased caveolin-1 expression in macrophages. J Lipid Res. 2003;44:1622-32.

58. Fielding CJ, Fielding PE. Caveolae and intracellular trafficking of cholesterol. Adv Drug Deliv Rev. 2001;49:251-64.

59. Burgermeister E, Liscovitch M, Rocken C, Schmid RM, Ebert MPA. Caveats of caveolin-1 in cancer progression. Cancer Lett. 2008;268:187-201.

60. Goetz JG, Lajoie P, Wiseman SM, Nabi IR. Caveolin-1 in tumor progression: the good, the bad and the ugly. Cancer Metastasis Rev. 2008;27:715-35.

61. Nguyen KCT, Cho KA. Versatile functions of caveolin-1 in aging-related diseases. Chonnam Med J. 2017:53:28-36.

62. Pavlides S, Gutierrez-Pajares JL, Katiyar S, Jasmin J, Mercier I, Walters R, Pavlides C, Pestell RG, Lisanti MP, Frank PG. Caveolin-1 regulates the antiatherogenic properties of macrophages. Cell Tissue Res. 2014;358:821-31.

63. Fernandez-Hernando C, Yu J, Suarez Y, Rahner C, Davalos A, Lasuncion MA, Sessa WC. Genetic evidence supporting a critical role of endothelial caveolin-1 during the progression of atherosclerosis. Cell Metab. 2009;10:48-54.

64. Stary CM, Tsutsumi YM, Patel PM, Head BP, Patel HH, Roth DM. Caveolins: targeting pro-survival signaling in the heart and brain. Front Physiol. 2012;3:393. 
65. Choi KH, Kim HS, Park MS, Lee EB, Lee JK, Kim JT, Kim JH, Lee MC, Lee HJ, Cho $\mathrm{KH}$. Overexpression of caveolin-1 attenuates brain edema by inhibiting tight junction degradation. Oncotarget. 2016;7:67857-67.

66. Jasmin J, Malhotra S, Singh Dhallu M, Mercier I, Rosenbaum DM, Lisanti MP. Caveolin-1 deficiency increases cerebral ischemic injury. Circ Res. 2007;100(5): 721-9. https://doi.org/10.1161/01.RES.0000260180.42709.29 Epub 2007 Feb 9.

67. Choi K, Kim H, Park M, Kim J, Kim J, Cho K, Lee M, Lee H, Cho K. Regulation of caveolin-1 expression determines early brain edema after experimental focal cerebral ischemia. Stroke. 2016;47:1336-43.

68. Zhang S, Liu Y, Zhao Z, Xue Y. Effects of green tea polyphenols on caveolin1 of microvessel fragments in rats with cerebral ischemia. Neurol Res. 2010; 32:963-70.

69. Huang P, Zhou C, Qin-Hu LY, Hu B, Chang X, Zhao X, Xu X, Li Q, Wei X, et al. Cerebralcare Granule(R) attenuates blood-brain barrier disruption after middle cerebral artery occlusion in rats. Exp Neurol. 2012;237:453-63.

70. Gu Y, Zheng G, Xu M, Li Y, Chen X, Zhu W, Tong Y, Chung SK, Liu KJ, Shen J. Caveolin-1 regulates nitric oxide-mediated matrix metalloproteinases activity and blood-brain barrier permeability in focal cerebral ischemia and reperfusion injury. J Neurochem. 2012;120:147-56.

71. Castellanos M, van Eendenburg C, Gubern C, Kadar E, Huguet G, Puig J, Sobrino T, Blasco G, Serena J, Sanchez JM. Low levels of caveolin-1 predict symptomatic bleeding after thrombolytic therapy in patients with acute ischemic stroke. Stroke. 2018;49:1525-7.

72. Preston JE, Joan Abbott N, Begley DJ. Transcytosis of macromolecules at the blood-brain barrier. Advances in pharmacology (San Diego, Calif). 2014;71: 147-63.

73. Soares ES, Mendonca MCP, Irazusta SP, Coope A, Stavale LM, da CruzHofling MA. Evidences of endocytosis via caveolae following blood-brain barrier breakdown by Phoneutria nigriventer spider venom. Toxicol Lett. 2014;229:415-22.

74. Schubert W, Frank PG, Razani B, Park DS, Chow CW, Lisanti MP. Caveolaedeficient endothelial cells show defects in the uptake and transport of albumin in vivo. J Biol Chem. 2001;276:48619-22.

75. Deng J, Huang Q, Wang F, Liu Y, Wang Z, Wang Z, Zhang Q, Lei B, Cheng Y. The role of caveolin-1 in blood-brain barrier disruption induced by focused ultrasound combined with microbubbles. J Mol Neurosci. 2012;46:677-87.

76. Feng Y, Venema VJ, Venema RC, Tsai N, Behzadian MA, Caldwell RB. VEGFinduced permeability increase is mediated by caveolae. Invest Ophthalmol Vis Sci. 1999:40:157-67.

77. Knowland D, Arac A, Sekiguchi KJ, Hsu M, Lutz SE, Perrino J, Steinberg GK, Barres BA, Nimmerjahn A, Agalliu D. Stepwise recruitment of transcellular and paracellular pathways underlies blood-brain barrier breakdown in stroke. Neuron. 2014;82:603-17.

78. Sverdlov M, Shajahan AN, Minshall RD. Tyrosine phosphorylation-dependence of caveolae-mediated endocytosis. J Cell Mol Med. 2007;11:1239-50.

79. Xu L, Guo R, Xie Y, Ma M, Ye R, Liu X. Caveolae: molecular insights and therapeutic targets for stroke. Expert Opin Ther Tar. 2015;19:633-50.

80. Sun Y, Hu G, Zhang X, Minshall RD. Phosphorylation of caveolin-1 regulates oxidant-induced pulmonary vascular permeability via paracellular and transcellular pathways. Circ Res. 2009;105:676-85 15-685.

81. Takeuchi K, Morizane Y, Kamami-Levy C, Suzuki J, Kayama M, Cai W, Miller JW, Vavvas DG. AMP-dependent kinase inhibits oxidative stress-induced caveolin-1 phosphorylation and endocytosis by suppressing the dissociation between c-Abl and Prdx1 proteins in endothelial cells. J Biol Chem. 2013; 288:20581-91.

82. Andreone BJ, Chow BW, Tata A, Lacoste B, Ben-Zvi A, Bullock K, Deik AA, Ginty DD, Clish CB, Gu C. Blood-brain barrier permeability is regulated by lipid transport-dependent suppression of caveolae-mediated transcytosis. Neuron. 2017:94:581-94.

83. Li Y, Liu L, Ma T, Wang P, Xue Y. Effect of caveolin-1 on the expression of tight junction-associated proteins in rat glioma-derived microvascular endothelial cells. Int J Clin Exp Pathol. 2015:8:13067-74.

84. Jin $X$, Sun $Y, X u$ J, Liu W. Caveolin-1 mediates tissue plasminogen activatorinduced MMP-9 up-regulation in cultured brain microvascular endothelial cells. J Neurochem. 2015;132:724-30.

85. Song $H$, Cheng $Y, B i ~ G, Z h u Y$, Jun $W$, Ma W, Wu H. Release of matrix metalloproteinases- 2 and 9 by S-nitrosylated caveolin-1 contributes to degradation of extracellular matrix in tPA-treated hypoxic endothelial cells. PLoS One. 2016;11:e149269.

86. Liu J, Jin X, Liu KJ, Liu W. Matrix metalloproteinase-2-mediated occludin degradation and caveolin-1-mediated claudin-5 redistribution contribute to blood-brain barrier damage in early ischemic stroke stage. J Neurosci. 2012; 32(9):3044-57. https://doi.org/10.1523/JNEUROSCl.6409-11.2012.

87. Liu J, Weaver J, Jin X, Zhang Y, Xu J, Liu KJ, Li W, Liu W. Nitric oxide interacts with caveolin-1 to facilitate autophagy-lysosome-mediated claudin-5 degradation in oxygen-glucose deprivation-treated endothelial cells. Mol Neurobiol. 2016;53:5935-47.

88. Stamatovic SM, Keep RF, Wang MM, Jankovic I, Andjelkovic AV. Caveolaemediated internalization of occludin and claudin-5 during CCL2-induced tight junction remodeling in brain endothelial cells. J Biol Chem. 2009;284:19053-66.

89. Liu W, Wang Z, Wang Y, Tong L, Li Y, Wei X, Luan P, Li L. Increasing the permeability of the blood-brain barrier in three different models in vivo. CNS Neurosci Ther. 2015;21:568-74.

90. Xie H, Lu W. Inhibition of transient receptor potential vanilloid 4 decreases the expressions of caveolin-1 and caveolin-2 after focal cerebral ischemia and reperfusion in rats. Neuropathology. 2018. https://doi.org/10.1111/neup. 12469. [Epub ahead of print].

91. Zou R, Wu Z, Cui S. Electroacupuncture pretreatment attenuates bloodbrain barrier disruption following cerebral ischemia/reperfusion. Mol Med Rep. 2015;12:2027-34.

92. del Zoppo GJ, Mabuchi T. Cerebral microvessel responses to focal ischemia. J Cereb Blood Flow Metab. 2003:23:879-94.

93. Krupinski J, Kaluza J, Kumar P, Kumar S, Wang JM. Role of angiogenesis in patients with cerebral ischemic stroke. Stroke. 1994;25:1794-8.

94. Hayashi T, Noshita N, Sugawara T, Chan PH. Temporal profile of angiogenesis and expression of related genes in the brain after ischemia. J Cereb Blood Flow Metab. 2003;23:166-80.

95. Carmeliet P, Collen D. Molecular basis of angiogenesis. Role of VEGF and VEcadherin. Ann N Y Acad Sci. 2000;902:249-62.

96. Feng $Y$, Vom Hagen F, Wang $Y$, Beck S, Schreiter K, Pfister F, Hoffmann S, Wagner $P$, Seeliger M, Molema $G$, et al. The absence of angiopoietin-2 leads to abnormal vascular maturation and persistent proliferative retinopathy. Thromb Haemost. 2009:102:120-30.

97. Yang J, Liu H, Liu X. VEGF promotes angiogenesis and functional recovery in stroke rats. J Investig Surg. 2010;23(3):149-55. https://doi.org/10.3109/ 08941930903469482

98. Seto S, Chang D, Jenkins A, Bensoussan A, Kiat H. Angiogenesis in ischemic stroke and angiogenic effects of Chinese herbal medicine. Journal of clinical medicine. 2016;5(6):56

99. Gao Y, Zhao Y, Pan J, Yang L, Huang T, Feng X, Li C, Liang S, Zhou D, Liu C, et al. Treadmill exercise promotes angiogenesis in the ischemic penumbra of rat brains through caveolin-1NEGF signaling pathways. Brain Res. 2014;1585:83-90.

100. Tu F, Pang Q, Chen X, Huang T, Liu M, Zhai Q. Angiogenic effects of apigenin on endothelial cells after hypoxia-reoxygenation via the caveolin-1 pathway. Int J Mol Med. 2017:40:1639-48.

101. Liu J, Wang XB, Park DS, Lisanti MP. Caveolin-1 expression enhances endothelial capillary tubule formation. J Biol Chem. 2002;277:10661-8.

102. Fang K, Fu W, Beardsley AR, Sun X, Lisanti MP, Liu J. Overexpression of caveolin-1 inhibits endothelial cell proliferation by arresting the cell cycle at G0/G1 phase. Cell Cycle. 2007;6(2):199-204. https://doi.org/10.4161/cc.6.2. 3740 Epub 2007 Jan 20.

103. Liu J, Razani B, Tang S, Terman BI, Ware JA, Lisanti MP. Angiogenesis activators and inhibitors differentially regulate caveolin-1 expression and caveolae formation in vascular endothelial cells. Angiogenesis inhibitors block vascular endothelial growth factor-induced down-regulation of caveolin-1. J Biol Chem. 1999;274:15781-5.

104. Labrecque L, Royal I, Surprenant DS, Patterson C, Gingras D, Beliveau R. Regulation of vascular endothelial growth factor receptor-2 activity by caveolin-1 and plasma membrane cholesterol. Mol Biol Cell. 2003;14:334-47.

105. Sonveaux P, Martinive P, DeWever J, Batova Z, Daneau G, Pelat M, Ghisdal P, Gregoire V, Dessy C, Balligand J, Feron O. Caveolin-1 expression is critical for vascular endothelial growth factor-induced ischemic hindlimb collateralization and nitric oxide-mediated angiogenesis. Circ Res. 2004;95:154-61.

106. Pan Y, Yao Y, Zhu Z, Sun X, Qiu Y, Ding Y. Caveolin-1 is important for nitric oxide-mediated angiogenesis in fibrin gels with human umbilical vein endothelial cells. Acta Pharmacol Sin. 2006;27:1567-74.

107. Koh S, Park H. Neurogenesis in stroke recovery. Transl Stroke Res. 2017:8:3-13.

108. Sakaguchi M, Okano H. Neural stem cells, adult neurogenesis, and galectin1: from bench to bedside. Dev Neurobiol. 2012;72:1059-67.

109. Faiz M, Sachewsky N, Gascon S, Bang KWA, Morshead CM, Nagy A. Adult neural stem cells from the subventricular zone give rise to reactive astrocytes in the cortex after stroke. Cell Stem Cell. 2015;17:624-34. 
110. Zhang RL, Zhang ZG, Zhang L, Chopp M. Proliferation and differentiation of progenitor cells in the cortex and the subventricular zone in the adult rat after focal cerebral ischemia. Neuroscience. 2001;105:33-41.

111. Jin K, Minami M, Lan JQ, Mao XO, Batteur S, Simon RP, Greenberg DA. Neurogenesis in dentate subgranular zone and rostral subventricular zone after focal cerebral ischemia in the rat. P Natl Acad Sci Usa. 2001; 98:4710-5.

112. Zhao Y, Pang Q, Liu M, Pan J, Xiang B, Huang T, Tu F, Liu C, Chen X. Treadmill exercise promotes neurogenesis in ischemic rat brains via caveolin-1/NEGF signaling pathways. Neurochem Res. 2017;42:389-97.

113. Pang Q, Zhang H, Chen Z, Wu Y, Bai M, Liu Y, Zhao Y, Tu F, Liu C, Chen X. Role of caveolin-1/vascular endothelial growth factor pathway in basic fibroblast growth factor-induced angiogenesis and neurogenesis after treadmill training following focal cerebral ischemia in rats. Brain Res. 2017;1663:9-19.

114. Li Y, Luo J, Lau W, Zheng G, Fu S, Wang T, Zeng H, So K, Chung SK, Tong Y, et al. Caveolin-1 plays a crucial role in inhibiting neuronal differentiation of neural stem/progenitor cells via VEGF signaling-dependent pathway. PLoS One. 2011;6:e22901.

115. Liu Y, Liang Z, Liu J, Zou W, Li X, Wang Y, An L. Downregulation of caveolin1 contributes to the synaptic plasticity deficit in the hippocampus of aged rats. Neural Regen Res. 2013;8:2725-33.

116. Cui W, Ren Y, Wang S, Zeng M, Han S, Li J, Han R. The role of caveolin-1 in morphine-induced structural plasticity in primary cultured mouse cerebral cortical neurons. Neurosci Lett. 2018;665:38-42.

117. Mandyam CD, Schilling JM, Cui W, Egawa J, Niesman IR, Kellerhals SE, Staples MC, Busija AR, Risbrough VB, Posadas E, et al. Neuron-targeted caveolin-1 improves molecular signaling, plasticity, and behavior dependent on the hippocampus in adult and aged mice. Biol Psychiatry. 2017;81:101-10.

118. Egawa J, Zemljic-Harpf A, Mandyam CD, Niesman IR, Lysenko LV, Kleschevnikov AM, Roth DM, Patel HH, Patel PM, Head BP. Neuron-targeted caveolin-1 promotes ultrastructural and functional hippocampal synaptic plasticity. Cerebral cortex (New York, NY : 1991). 2017:1-12.

119. Head BP, Hu Y, Finley JC, Saldana MD, Bonds JA, Miyanohara A, Niesman IR, Ali SS, Murray F, Insel PA, et al. Neuron-targeted caveolin-1 protein enhances signaling and promotes arborization of primary neurons. J Biol Chem. 2011;286:33310-21.

120. Head BP, Patel HH, Tsutsumi YM, Hu Y, Mejia T, Mora RC, Insel PA, Roth DM, Drummond JC, Patel PM. Caveolin-1 expression is essential for N-methyl-Daspartate receptor-mediated Src and extracellular signal-regulated kinase 1/ 2 activation and protection of primary neurons from ischemic cell death. FASEB J. 2008;22:828-40.

121. Consales C, Volpicelli F, Greco D, Leone L, Colucci-D'Amato L, PerroneCapano C, di Porzio U. GDNF signaling in embryonic midbrain neurons in vitro. Brain Res. 2007;1159:28-39.

122. de Almeida CJG. Caveolin-1 and Caveolin-2 can be antagonistic partners in inflammation and beyond. Front Immunol. 2017;8:1530.

123. Sifat AE, Vaidya B, Abbruscato TJ. Blood-brain barrier protection as a therapeutic strategy for acute ischemic stroke. AAPS J. 2017;19:957-72.

124. Niesman IR, Schilling JM, Shapiro LA, Kellerhals SE, Bonds JA, Kleschevnikov AM, Cui W, Voong A, Krajewski S, Ali SS, et al. Traumatic brain injury enhances neuroinflammation and lesion volume in caveolin deficient mice. J Neuroinflammation. 2014;11:39.

125. Jiang Y, Lin X, Tang Z, Lee C, Tian G, Du Y, Yin X, Ren X, Huang L, Ye Z, et al. Critical role of caveolin-1 in ocular neovascularization and multitargeted antiangiogenic effects of cavtratin via JNK. P Natl Acad Sci Usa. 2017;114:10737-42.

126. Argaw AT, Asp L, Zhang J, Navrazhina K, Pham T, Mariani JN, Mahase S, Dutta DJ, Seto J, Kramer EG, et al. Astrocyte-derived VEGF-A drives blood-brain barrier disruption in CNS inflammatory disease. J Clin Invest. 2012;122:2454-68.

127. Bucci M, Gratton JP, Rudic RD, Acevedo L, Roviezzo F, Cirino G, Sessa WC. In vivo delivery of the caveolin-1 scaffolding domain inhibits nitric oxide synthesis and reduces inflammation. Nat Med. 2000;6:1362-7.

128. Harris J, Werling D, Hope JC, Taylor G, Howard CJ. Caveolae and caveolin in immune cells: distribution and functions. Trends Immunol. 2002;23:158-64.

129. Li J, Scherl A, Medina F, Frank PG, Kitsis RN, Tanowitz HB, Sotgia F, Lisanti MP. Impaired phagocytosis in caveolin-1 deficient macrophages. Cell Cycle. 2005:4:1599-607.

130. Jiao H, Zhang Y, Yan Z, Wang Z, Liu G, Minshall RD, Malik AB, Hu G. Caveolin-1 Tyr14 phosphorylation induces interaction with TLR4 in endothelial cells and mediates MyD88-dependent signaling and sepsisinduced lung inflammation. J Immunol. 2013;191:6191-9.
131. Matsui T, Higashimoto Y, Taira J, Yamagishi S. Pigment epithelium-derived factor (PEDF) binds to caveolin-1 and inhibits the pro-inflammatory effects of caveolin-1 in endothelial cells. Biochem Bioph Res Co. 2013;441:405-10.

132. Oakley FD, Smith RL, Engelhardt JF. Lipid rafts and caveolin-1 coordinate interleukin-1 beta (IL-1 beta)-dependent activation of NFkappaB by controlling endocytosis of Nox2 and IL-1 beta receptor 1 from the plasma membrane. J Biol Chem. 2009;284:33255-64.

133. Garrean S, Gao X, Brovkovych V, Shimizu J, Zhao Y, Vogel SM, Malik AB. Caveolin-1 regulates NF-kappaB activation and lung inflammatory response to sepsis induced by lipopolysaccharide. J Immunol. 2006;177:4853-60.

134. Mirza MK, Yuan J, Gao X, Garrean S, Brovkovych V, Malik AB, Tiruppathi C, Zhao Y. Caveolin-1 deficiency dampens Toll-like receptor 4 signaling through eNOS activation. Am J Pathol. 2010;176:2344-51.

135. Wang XM, Kim HP, Song R, Choi AMK. Caveolin-1 confers antiinflammatory effects in murine macrophages via the MKK3/p38 MAPK pathway. Am J Resp Cell Mol. 2006;34:434-42.

136. Wang XM, Kim HP, Nakahira K, Ryter SW, Choi AMK. The heme oxygenase-1/ carbon monoxide pathway suppresses TLR4 signaling by regulating the interaction of TLR4 with caveolin-1. J Immunol. 2009;182:3809-18.

137. Hu G, Ye RD, Dinauer MC, Malik AB, Minshall RD. Neutrophil caveolin-1 expression contributes to mechanism of lung inflammation and injury. Am J Physiol Lung Cell Mol Physiol. 2008;294:L178-86.

138. Ohnuma K, Inoue H, Uchiyama M, Yamochi T, Hosono O, Dang NH, Morimoto C. T-cell activation via CD26 and caveolin-1 in rheumatoid synovium. Mod Rheumatol. 2006;16:3-13.

139. Feng H, Guo L, Song Z, Gao H, Wang D, Fu W, Han J, Li Z, Huang B, Li X. Caveolin-1 protects against sepsis by modulating inflammatory response, alleviating bacterial burden, and suppressing thymocyte apoptosis. J Biol Chem. 2010;285:25154-60.

140. Portugal CC, Socodato R, Canedo T, Silva CM, Martins T, Coreixas VSM, Loiola EC, Gess B, Rohr D, Santiago AR, et al. Caveolin-1-mediated internalization of the vitamin C transporter SVCT2 in microglia triggers an inflammatory phenotype. Sci Signal. 2017;10. https://doi.org/10.1126/ scisignal.aal2005.

141. Kagawa Y, Yasumoto Y, Sharifi K, Ebrahimi M, Islam A, Miyazaki H, Yamamoto Y, Sawada T, Kishi H, Kobayashi S, et al. Fatty acid-binding protein 7 regulates function of caveolae in astrocytes through expression of caveolin-1. Glia. 2015; 63:780-94.

142. Feng H, Guo W, Han J, Li X. Role of caveolin-1 and caveolae signaling in endotoxemia and sepsis. Life Sci. 2013;93:1-6.

143. Candelario-Jalil E, Gonzalez-Falcon A, Garcia-Cabrera M, Leon OS, Fiebich BL. Post-ischaemic treatment with the cyclooxygenase-2 inhibitor nimesulide reduces blood-brain barrier disruption and leukocyte infiltration following transient focal cerebral ischaemia in rats. J Neurochem. 2007;100:1108-20.

144. Chen S, Liou J, Huang T, Lin Y, Yeh A, Tam K, Tsai T, Wu KK, Shyue S. Caveolin-1 facilitates cyclooxygenase-2 protein degradation. J Cell Biochem. 2010;109:356-62.

145. Kerr JF, Wyllie AH, Currie AR. Apoptosis: a basic biological phenomenon with wide-ranging implications in tissue kinetics. Brit J Cancer. 1972;26: 239-57.

146. Festjens N, Vanden Berghe T, Vandenabeele P. Necrosis, a well-orchestrated form of cell demise: signalling cascades, important mediators and concomitant immune response. Biochim Biophys Acta. 2006;1757:1371-87.

147. Codogno P, Meijer AJ. Autophagy and signaling: their role in cell survival and cell death. Cell Death Differ. 2005;12(Suppl 2):1509-18.

148. Hellwig CT, Passante $E$, Rehm M. The molecular machinery regulating apoptosis signal transduction and its implication in human physiology and pathophysiologies. Curr Mol Med. 2011;11:31-47.

149. Quest AFG, Lobos-Gonzalez L, Nunez S, Sanhueza C, Fernandez J, Aguirre A, Rodriguez D, Leyton L, Torres V. The caveolin-1 connection to cell death and survival. Curr Mol Med. 2013;13:266-81.

150. Zhang W, Yokota H, Xu Z, Narayanan SP, Yancey L, Yoshida A, Marcus DM, Caldwell RW, Caldwell RB, Brooks SE. Hyperoxia therapy of pre-proliferative ischemic retinopathy in a mouse model. Invest Ophthalmol Vis Sci. 2011;52: 6384-95.

151. Glukhova XA, Trizna JA, Proussakova OV, Gogvadze V, Beletsky IP. Impairment of Fas-ligand-caveolin-1 interaction inhibits Fas-ligand translocation to rafts and Fas-ligand-induced cell death. Cell Death Dis. 2018;9:73.

152. Tait SWG, Green DR. Mitochondria and cell death: outer membrane permeabilization and beyond. Nat Rev Mol Cell Biol. 2010;11:621-32. 
153. Chen Y, Lin W, Liu C, Su S. H2O2 induces caveolin1 degradation and impaired mitochondrial function in E11 podocytes. Mol Med Rep. 2017;16:7841-7.

154. Shiroto T, Romero N, Sugiyama T, Sartoretto IL, Kalwa H, Yan Z, Shimokawa H, Michel T. Caveolin-1 is a critical determinant of autophagy, metabolic switching, and oxidative stress in vascular endothelium. PLoS One. 2014:9:e87871.

155. Bosch M, Mari M, Herms A, Fernandez A, Fajardo A, Kassan A, Giralt A, Colell A, Balgoma D, Barbero E, et al. Caveolin-1 deficiency causes cholesteroldependent mitochondrial dysfunction and apoptotic susceptibility. Curr Biol. 2011;21:681-6.

156. Volonte D, Liu Z, Shiva S, Galbiati F. Caveolin-1 controls mitochondrial function through regulation of $\mathrm{m}$-AAA mitochondrial protease. Aging. 2016; 8:2355-69.

157. Torres VA, Tapia JC, Rodriguez DA, Parraga M, Lisboa P, Montoya M, Leyton L, Quest AFG. Caveolin-1 controls cell proliferation and cell death by suppressing expression of the inhibitor of apoptosis protein survivin. J Cell Sci. 2006;119:1812-23.

158. Shen J, Lee W, Li Y, Lau CF, Ng KM, Fung ML, Liu KJ. Interaction of caveolin1, nitric oxide, and nitric oxide synthases in hypoxic human SK-N-MC neuroblastoma cells. J Neurochem. 2008;107:478-87.

159. Yue W, Yao S, Zhou X, Si Y, Sang H, Wang J, Shang Z. Inhibitory effect of caveolin-1 on endoplasmic reticulum stress-induced apoptosis in macrophages via p38 MAPK pathway. Sheng Li Xue Bao. 2012;64(2):149-54.

160. Kang J, Lee S. Impaired expression of caveolin-1 contributes to hepatic ischemia and reperfusion injury. Biochem Bioph Res Co. 2014:450:1351-7.

161. Xu L, Wang L, Wen Z, Wu L, Jiang Y, Yang L, Xiao L, Xie Y, Ma M, Zhu W, et al. Caveolin-1 is a checkpoint regulator in hypoxia-induced astrocyte apoptosis via Ras/Raf/ERK pathway. Am J Physiol Cell Physiol. 2016;310:C903-10.

162. Chen F, Barman S, Yu Y, Haigh S, Wang Y, Black SM, Rafikov R, Dou H, Bagi Z, Han W, et al. Caveolin-1 is a negative regulator of NADPH oxidasederived reactive oxygen species. Free Radic Biol Med. 2014;73:201-13.

163. Wang S, Wang N, Zheng Y, Zhang J, Zhang F, Wang Z. Caveolin-1: an oxidative stress-related target for cancer prevention. Oxidative Med Cell Longev. 2017;2017:7454031.

164. Yun JH, Park SJ, Jo A, Kang JL, Jou I, Park JS, Choi YH. Caveolin-1 is involved in reactive oxygen species-induced SHP-2 activation in astrocytes. Exp Mol Med. 2011;43:660-8.

165. Ju H, Zou R, Venema VJ, Venema RC. Direct interaction of endothelial nitricoxide synthase and caveolin-1 inhibits synthase activity. J Biol Chem. 1997; 272:18522-5.

166. Bernatchez PN, Bauer PM, Yu J, Prendergast JS, He P, Sessa WC. Dissecting the molecular control of endothelial NO synthase by caveolin-1 using cellpermeable peptides. P Natl Acad Sci Usa. 2005;102:761-6.

167. Phillips PG, Birnby LM. Nitric oxide modulates caveolin-1 and matrix metalloproteinase-9 expression and distribution at the endothelial cell/ tumor cell interface. Am J Physiol Lung Cell Mol Physiol. 2004;286:L1055-65.

168. Shen J, Ma S, Chan P, Lee W, Fung PCW, Cheung RTF, Tong Y, Liu KJ. Nitric oxide down-regulates caveolin-1 expression in rat brains during focal cerebral ischemia and reperfusion injury. J Neurochem. 2006:96:1078-89.

169. Garcia-Cardena G, Martasek P, Masters BS, Skidd PM, Couet J, Li S, Lisanti MP, Sessa WC. Dissecting the interaction between nitric oxide synthase (NOS) and caveolin. Functional significance of the nos caveolin binding domain in vivo. J Biol Chem. 1997;272:25437-40.

170. Michel JB, Feron O, Sacks D, Michel T. Reciprocal regulation of endothelial nitric-oxide synthase by Ca2+-calmodulin and caveolin. J Biol Chem. 1997; 272:15583-6.

171. Chidlow JHJ, Sessa WC. Caveolae, caveolins, and cavins: complex control of cellular signalling and inflammation. Cardiovasc Res. 2010;86:219-25.

172. Zhao Y, Zhao YD, Mirza MK, Huang JH, Potula HSK, Vogel SM, Brovkovych V, Yuan JX, Wharton J, Malik AB. Persistent eNOS activation secondary to caveolin-1 deficiency induces pulmonary hypertension in mice and humans through PKG nitration. J Clin Invest. 2009:119:2009-18.

Ready to submit your research? Choose BMC and benefit from:

- fast, convenient online submission

- thorough peer review by experienced researchers in your field

- rapid publication on acceptance

- support for research data, including large and complex data types

- gold Open Access which fosters wider collaboration and increased citations

- maximum visibility for your research: over $100 \mathrm{M}$ website views per year

At $\mathrm{BMC}$, research is always in progress.

Learn more biomedcentral.com/submissions 